\begin{abstract}
Title of Thesis:

COMPARING SOURCE OF AGRICULTURAL CONTACT WATER AND THE PRESENCE OF FECAL INDICATOR ORGANISMS ON THE SURFACE OF 'JULIET' GRAPE TOMATOES
\end{abstract}

Donna Marie Pahl, Master of Science, 2010

Thesis Directed by:

Professor Christopher S. Walsh

Department of Plant Science and Landscape Architecture

Microbial water quality standards exist to prevent food safety outbreaks due to the use of agricultural water, although little is known about how the levels the fecal indicator organisms in water relate to the counts on the tomato fruit surface. This study utilized fecal indicator organisms commonly used in microbial water quality standards (Enterobacteriaceae, total coliforms, fecal coliforms, and E. coli) to monitor the water quality of surface ponds, a groundwater source, and the phyllosphere of treated grape tomatoes over two growing seasons. Water source and date caused a significant difference in the counts of fecal indicator organisms. Variability in bacterial counts was found in the surface water sources over the course of the season, partially explained by environmental variables such as water temperature, $\mathrm{pH}$, precipitation, and air 
temperature. The microbial counts on the surfaces of the tomato fruit did not reflect the water treatments applied to the plants. 


\title{
COMPARING SOURCE OF AGRICULTURAL CONTACT WATER AND THE PRESENCE OF FECAL INDICATOR ORGANISMS ON THE SURFACE OF 'JULIET' GRAPE TOMATOES
}

\author{
by \\ Donna Marie Pahl \\ Thesis submitted to the Faculty of the Graduate School of the \\ University of Maryland, College Park in partial fulfillment \\ Of the requirements for the degree of \\ Master of Science \\ 2010
}

Advisory Committee:

Professor Christopher S. Walsh, Chair Associate Professor John Lea-Cox Dr. Michael Mahovic, USFDA Assistant Professor Amy R. Sapkota 


\section{Dedication}

For my mom and friend, Pamela Pahl, who together with my dad taught me that agriculture is a fun and rewarding field whether on or off the farm, and encouraged me throughout the experience of graduate school. 


\section{Acknowledgements}

I would like to thank my family for their encouragement and support throughout graduate school and research, especially through the busy summers.

Dr. Chris Walsh has been invaluable as an advisor and my most encouraging supporter. He pushed me as an undergraduate to begin research, and has challenged me as a graduate student in the classroom and field. Without Dr. Walsh, I would not have decided to "leave the farm" and start grad school. For this I am grateful.

I would like to thank my thesis committee, Dr. John Lea-Cox, Amy Sapkota, and Mike Mahovic, for their time and input into the project. Their assistance and questioning strengthened the science behind my research and fostered my abstract thinking.

Thank you Mike Newell and the staff at WREC for their invaluable help with keeping the tomato plots alive!

Adriana Telias offered her tireless help and friendship during data collection, statistics calculations, and thesis writing. Thank you!

Thanks to Demetra Skaltsas and Andrea Ottesen for teaching me lab techniques and how to conduct research, and to Brian Murphy for helping with lab work.

Julia Harshman offered her friendship and substantial support with lab work, ideas, and advice. Thank you! 


\section{Table of Contents}

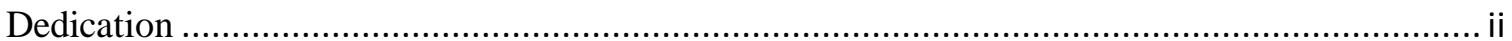

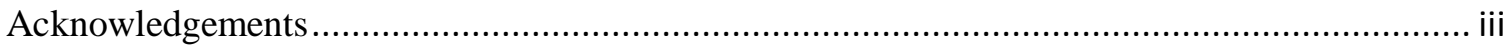

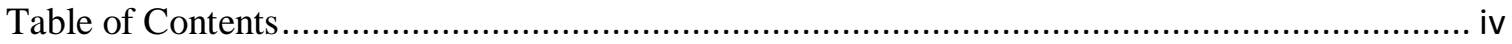

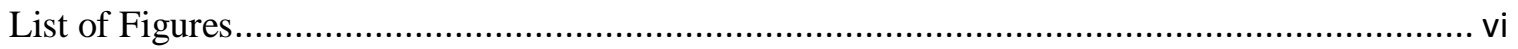

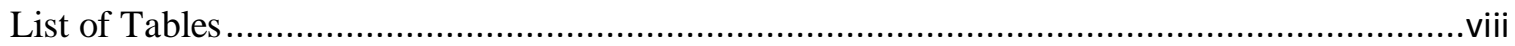

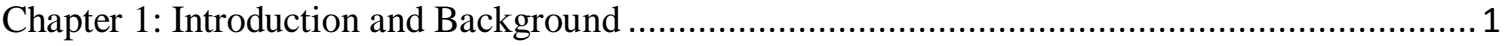

Food Safety Outbreaks on Tomatoes …............................................................................... 2

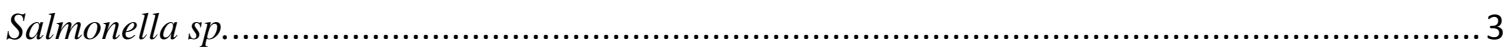

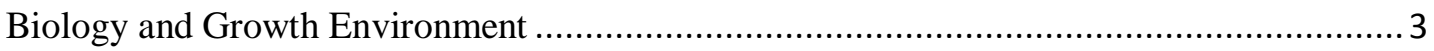

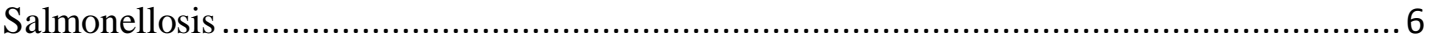

Tomato Biology and Associated Microflora …................................................................... 8

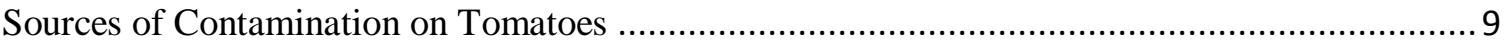

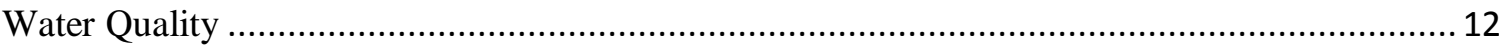

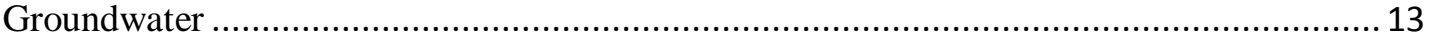

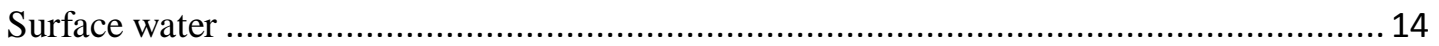

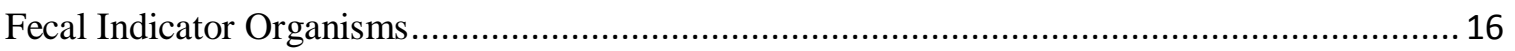

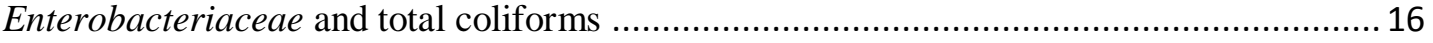

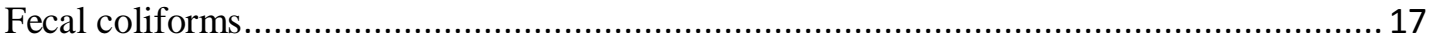

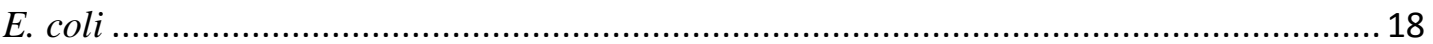

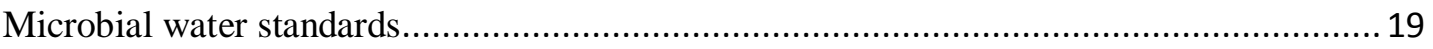

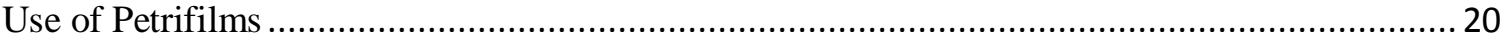

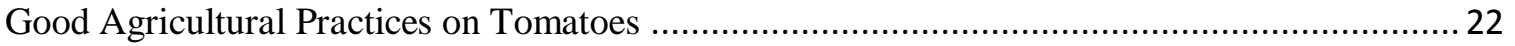

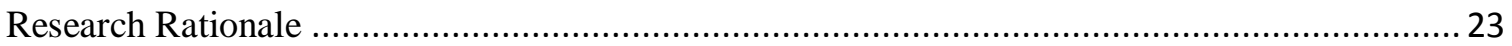

Chapter 2 : Comparing Source of Agricultural Contact Water and the Presence of Fecal Indicator Organisms on the Surface of 'Juliet' Grape Tomatoes ............................................................. 27

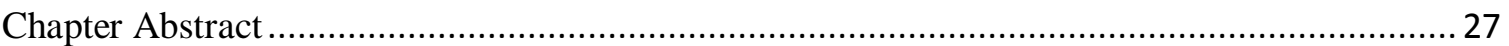

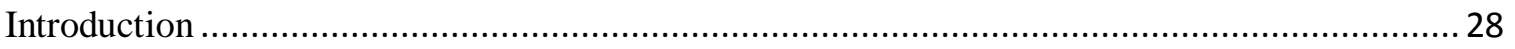

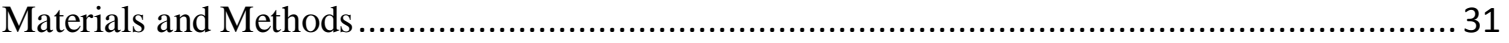

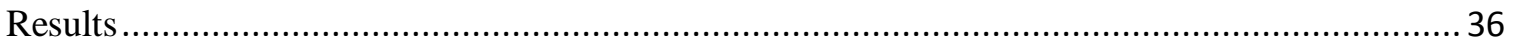

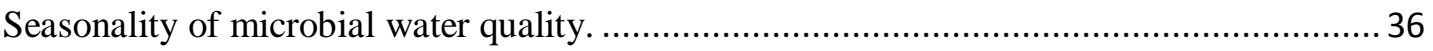


Effect of water quality on the microbial load of fecal indicator organisms on grape tomato

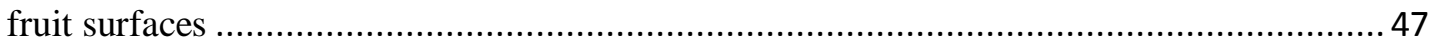

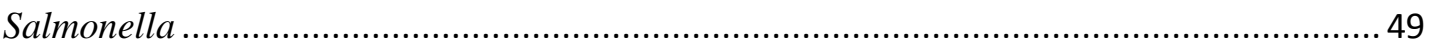

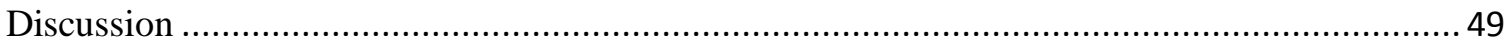

Chapter 3 : Effects of Tomato Maturity, Water Temperature and Water $\mathrm{pH}$ on Bacterial Counts of

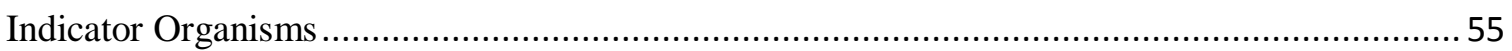

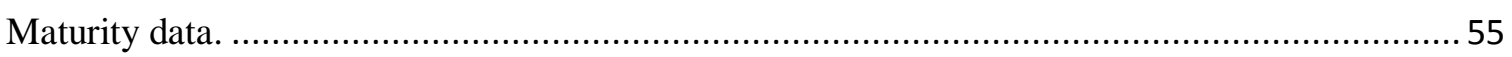

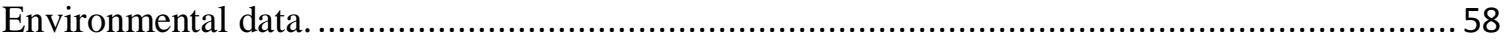

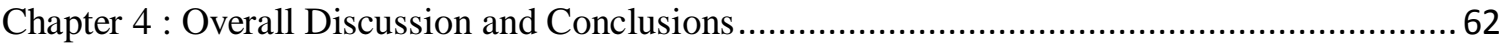

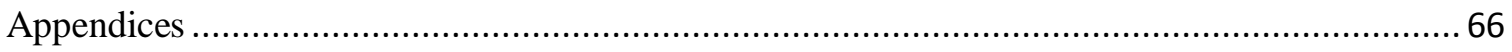

A.Map of Grape tomato plots (2009 and 2010) at Wye Research and Education Center (WREC).

'Trees' indicates a forested area 30 feet from tomato plot. ................................................ 66

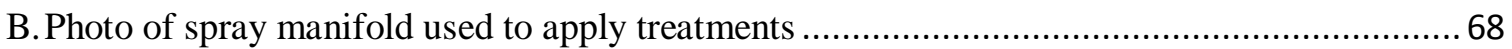

C.Spray schedules at the grape tomato field plots at WREC for the 2009 and 2010 sampling

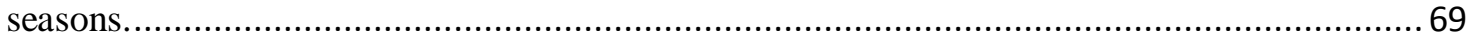

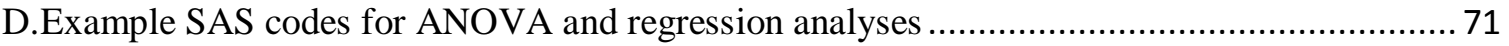

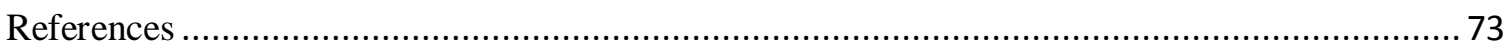




\section{List of Figures}

Figure 1-1. A visualization of the relationship between various fecal indicator organisms and three genera of pathogenic bacteria that cause food-borne illness. In this study, Enterobacteriaceae, total coliforms, fecal coliforms, and E. coli were used as fecal indicator organisms. Reproduced from: University of California, 2007.

Figure 2-1. Change of Enterobacteriaceae counts over the course of the 2009 sampling season. Organized by water source: groundwater (W-G), surface pond (W-S), and a copper-sulfate treated surface pond (W-CS). Counts are the log-transformed means (per $100 \mathrm{ml}$ ) of three replicates.... 38

Figure 2-2. Change of total coliform counts over the course of the 2009 sampling season. Organized by water source: W-G, W-S, and W-CS. Counts are the log-transformed means (per $100 \mathrm{ml}$ ) of three replicates.

Figure 2-3. Change of fecal coliform counts over the course of the 2009 sampling season. Organized by water source: W-G, W-S, and W-CS. Counts are the log-transformed means (per $100 \mathrm{ml}$ ) of three replicates.

Figure 2-4. Change of Enterobacteriaceae counts over the course of the 2010 sampling season. Organized by water source: W-G, W-S, and W-CS. Counts are the log-transformed means (per $100 \mathrm{ml}$ ) of three replicates

Figure 2-5. Change of total coliform counts over the course of the 2010 sampling season. Organized by water source: W-G, W-S, and W-CS. Counts are the log-transformed means (per $100 \mathrm{ml}$ ) of three replicates.

Figure 2-6. Change of fecal coliform counts over the course of the 2010 sampling season. Organized by water source: W-G, W-S, and W-CS. Counts are the log-transformed means (per $100 \mathrm{ml}$ ) of three replicates.

Figure 2-7. Change of E. coli counts over the course of the 2009 sampling season. Organized by water source: W-G, W-S, and W-CS. Counts are the log-transformed means (per $100 \mathrm{ml}$ ) of three replicates.

Figure 3-1. Effect of water temperature in W-S on the growth of three fecal indicator organisms, (Enterobacteriaceae, total coliforms, and fecal coliforms) during the 2009 sampling season......59

Figure 3-2. The effect of water temperature in W-CS on the growth of fecal indicator organisms (Enterobacteriaceae, total coliforms, and fecal coliforms) during the 2009 sampling season......59 
Figure 3-3. The effect of water temperature in W-S on the growth of fecal indicator organisms (Enterobacteriaceae, total coliforms, fecal coliforms, and E. coli) during the 2010 sampling season.

Figure 3-4. The effect of water temperature in W-CS on the growth of fecal indicator organisms (Enterobacteriaceae, total coliforms, fecal coliforms, and E. coli) during the 2010 sampling season.

Figure 3-5. The effect of $\mathrm{pH}$ in W-S on the growth of fecal indicator organisms

(Enterobacteriaceae, total coliforms, and fecal coliforms) during the 2009 sampling season...... 61 


\section{List of Tables}

Table 1-1. List of outbreaks associated with enteric human pathogens and tomatoes, 1990 to 2006.

Table 2-1. Level of four indicator organisms in two sample types (source and spray catch) across three water sources. Log-transformed data is reported as $\log \mathrm{CFU} / 100 \mathrm{ml}$, and is the mean of 3 repetitions and 4 sampling dates in 2010 (Tukey means comparison test, $\mathrm{P}<0.05$ ).

Table 2-2. Change in Enterobacteriaceae, total coliforms, fecal coliforms, and E. coli as described by several environmental variables over the 2009 and 2010 sampling seasons. Values are the coefficients of a regression equation (following a stepwise regression).

Table 2-3. Summary of 2009 and 2010 fecal indicator organism counts on grape tomato fruit surface, organized by water source treatments. Means are presented as Log CFU / $100 \mathrm{ml}$ water.

Table 3-1. Preliminary data comparing levels of fecal indicator organisms (Enterobacteriaceae, total coliforms, fecal coliforms, and $E$. coli) on different maturity levels of grape tomato fruit during two dates in 2010. Means are presented as Log CFU/ $100 \mathrm{ml}$. 


\section{Chapter 1: Introduction and Background}

Tomatoes are the world's second largest vegetable crop, with more than 70 million tons grown each year (FAO, 2008). After China, the United States is the world's second largest tomato producer and processor (FAO, 2008). Tomato production in the United States has increased in recent years, from 10,927,000 tonnes in 1990 to $13,718,171$ tonnes in 2008 (FAO, 2008). This fruit is used fresh in a variety of foodstuffs such as salads, sandwiches, soups, juices, salsas, and pasta dishes.

Food safety of produce can address a wide range of contaminants; in addition to biological contamination by pathogenic organisms, chemical and physical contamination are concerns as well. Chemical contamination may refer to pesticides, whereas physical contaminants may include shards of glass or wooden splinters from picking containers. A batch of produce containing any of the above contaminants may contaminate other batches, although only biological contaminants pose the risk of amplified growth prior to consumption (Fan et al., 2009). Due to the complexity of produce production, packing, and transportation, biological contamination can occur during any number of steps before the produce is consumed. Pathogens can be introduced into produce through animal waste such as manure, agricultural contact water, farm workers, and contaminated equipment (Fan et al., 2009). The number of foodborne outbreaks attributed to tomatoes has increased in recent years, with the majority of these cases caused by Salmonella enterica. In order to prevent such outbreaks, the United States Food and Drug Administration (FDA) is adopting science-based metrics that tomato producers may use as microbial standards. Any proposed metrics may include mandatory water quality 
standards to minimize the preharvest contamination of tomatoes via agricultural contact water such as irrigation and pesticide application water.

\section{Food Safety Outbreaks on Tomatoes}

It was once thought that fruits and vegetables were microbiologically safer than milk, meats, and other food sources (Sajur et al., 2007). Historically, the most common source of food-borne illness was from the consumption of seafood and poultry (Mead et al., 1999). However in recent years, the number of food-borne outbreaks resulting from fresh fruits and vegetables has increased, so that now fresh produce accounts for $29 \%$ of the total food-borne outbreaks (Beuchat, 2002). Between 1973 and 1997, the number of produce-associated outbreaks increased eight-fold (Sivapalasingam et al., 2004) . There is no single risk factor implicated in the increase in food-borne illnesses. (Fan et al., 2009). Reasons for the increase in cases of foodborne illnesses may be due to changes in dietary habits, the source of consumed produce, the methods of fruit production and processing, and the "emergence of pathogens previously not recognized for their association with raw produce" (Beuchat, 2002). Additionally, detection methods, trace-back ability, and reporting methods have improved as well. Better quality, year-round availability, and a greater variety of produce has led to an increase in consumption (Putnam and Allshouse, 1999). The complexity and variability of pre- and post-harvest practices, packinghouse activities, and the distribution system causes produce outbreaks to be more difficult to investigate and solve (Fan et al., 2009). 
Between 1970 and 1997, the yearly consumption of produce per capita increased by $24 \%$, from 573 pounds to 711 pounds (Sivapalasingam et al., 2004). Of the vegetables, ingestion of fresh tomatoes, onions and leafy greens increased in particular (Wells et al., 2008). Food-borne illnesses on tomatoes are of particular concern to scientists because the amount of tomato consumption is increasing (the United States now consumes 5 billion pounds of tomatoes annually). In 2005 alone, Americans ate 20.2 pounds of fresh tomatoes per capita, a 66\% increase from the 12.1 pounds eaten in 1970 (Wells et al., 2008). Between 1996 and 2008, tomatoes were responsible for $17.1 \%$ of produce outbreaks. See Table 1-1 for a listing of recent tomato outbreaks. Additionally, tomatoes are frequently eaten without being cooked, so that there is no kill-step, or heating step to inactivate microbes, before the fruit is eaten (Matthews 2006).

\section{Salmonella sp.}

\section{Biology and Growth Environment}

The majority of food-borne illnesses in tomatoes are caused by Salmonella enterica, a gram-negative facultative anaerobe that causes serious gastrointestinal illness in humans (Montville et al., 2008). A member of the family Enterobacteriaceae, the rodshaped Salmonella have peritrichous flagella that allow them to be motile in moist environments. Salmonella grows at the optimum temperatures of $35-40^{\circ} \mathrm{C}$, a range which encompasses the body temperature of humans $\left(37^{\circ} \mathrm{C}\right)$, allowing it to incubate in the human body. Salmonella is adaptable to extreme environmental conditions. Depending

upon the serovar, S. enterica can exhibit both heat-tolerant and psychrotrophic properties 
(Montville et al., 2008). S. enterica serovar Typhimurium may survive at temperatures as low as $2^{\circ} \mathrm{C}$ for up to $24 \mathrm{hrs}$ in minced beef, and $S$. Enteritidis on egg shells may survive for up to 10 days at $4{ }^{\circ} \mathrm{C}$. Thus, some Salmonella serovars may survive on refrigerated foods during storage (Montville et al., 2008). Bacteria surviving in environments outside of their optimum temperatures may be at a lag stage where reproduction is greatly reduced because they must adjust to the new environment. On a simple agar medium, $S$. Typhimurium can survive at temperatures up to $54^{\circ} \mathrm{C}$ (Montville et al., 2008). In addition to the individual serovar's response to temperature changes, factors such as the water activity and composition of the freezing and heating matrix play large roles in the ability of Salmonella to withstand temperature changes. When heated, matrices with high water activity increase a bacterium's heat resistance. Salmonella is able to acquire resistance to high temperatures by changing the fatty acid composition of cell membranes. Increasing the amount of phospholipids decreases rigidity of the membrane, allowing the membrane to resist heat damage (Montville et al., 2008). The wide temperature tolerance exhibited by Salmonella enables it to survive a range of environments, making it potentially difficult to kill while sanitizing produce.

Similar to temperature, Salmonella is able to withstand environments with a range of $\mathrm{pH}$ values. Optimal growth occurs between 6.5 to 7.5 , although Salmonella can survive in environments with $\mathrm{pH} 4.0$ to 9.0. This $\mathrm{pH}$ range includes that of tomato fruit, especially in field conditions during tomato season (Buchanan, 2010; Matthews, 2006). The acid tolerance of Salmonella depends on a range of factors, which may include $\mathrm{pH}$, the type and concentration of the acidulant, the temperature, and the cell's pre-adaption to the environment (Montville et al., 2008). If bacteria are surviving in a non-optimum 
environment, they will already be stressed and are less likely to survive highly acidic conditions. While the $\mathrm{pH}$ is outside the level that supports growth, bacteria will maintain homeostasis until the cell's energy stores are depleted. Soon after, the bacteria will dieoff. Additionally, bacteria in the stationary growth phase are more likely to survive longer than bacteria in the exponential growth phase, because those in the exponential phase are actively respiring and reproducing, and therefore using more energy. The acidulant identity is important when determining the bacteria's acid tolerance, because both the anion and proton $\left(\mathrm{H}^{+}\right)$affect the bacteria (Montville et al., 2008). Once acidic molecules separate into a proton and anion, the protons diffuse into the cell membrane and force bacteria to actively pump protons out of the cell (Sylvia et al., 2005). Meanwhile, the anions may have an effect on inactivation time by protecting cells or killing them. Acetic acid, for example, is a popular food sanitizer because both the proton and anion negatively affect bacterial cells (Montville et al., 2008).

In otherwise optimal environments, Salmonella spp. can exhibit an acid tolerance response that enables the microorganism to survive in extremely high acid environments, such as a human stomach, for a short amount of time. When exposed to such environments, Salmonella reduces its growth rate and induces the synthesis of over forty outer membrane proteins which enable $\mathrm{pH}$ homeostasis of the cell's cytoplasm (Montville et al., 2008). The bacteria's tolerance to acidity should be taken into account when developing guidelines for produce sanitation, since subjecting the microbe only to highly acidic environments may not be effective. Additionally, when Salmonella was inoculated onto fresh-cut produce, Salmonella strains that would normally be killed in the acidic experimental environment ( $\mathrm{pH} 3.0$ at $37^{\circ} \mathrm{C}$ for $2 \mathrm{~h}$ ) survived (Montville et al., 
2008). It was suggested that the cellulose matrix within produce may play a protective role (Matthews, 2006). Sanitation practices may also need to stress the bacteria with other means, such as decreased temperatures.

\section{Salmonellosis}

With greater than 2,500 serovars, Salmonella sp. is the leading cause of foodborne illness: an estimated 1.4 million cases of salmonellosis occur annually, with about 400 associated deaths (Daly et al., 2010; Montville et al., 2008). Tomatoes are currently the most implicated produce for produce-associated salmonellosis, with 12 outbreaks since 1998 (Barak and Liang, 2008; Fan et al., 2009). Between 1973 and 1997 there were only three tomato outbreaks. Salmonella enterica serovar Javiana and the virus hepatitis A each caused one outbreak, with one outbreak cause remaining unknown (Fan et al., 2009). Together, these outbreaks sickened 234 people, causing 18 hospitalizations and one death (Sivapalasingam et al., 2004). Between 1990 and 1994 nine outbreaks of Salmonella caused 1,616 illnesses. In 2004 alone there were three outbreaks of salmonellosis on Roma tomatoes in the United States and Canada. Three separate serotypes of Salmonella enterica were the cause of infection: Javiana, Typhimurium, and Anatum (Buchanan, 2010; Sivapalasingam et al., 2004).

Salmonella infections in humans can lead to several conditions, including typhoid fever, enterocolitis, and systemic infections. Food-borne salmonellosis is often caused by ingesting nontyphoid organisms. The onset of symptoms usually occurs between 12-72 hours after ingestion. Salmonellosis causes acute enteritis, including diarrhea, nausea, abdominal pain, headaches, and chills, and can occasionally include vomiting, weakness, 
and drowsiness (Cummings et al., 2010; Matthews, 2006; Montville et al., 2008).

Recovery usually takes about 1-5 days. Immuno-compromised individuals, infants, and the elderly are those most susceptible to salmonellosis, although the infection risk can also depend on the virulence of the pathogen, as well as the chemical composition of contaminated food. Foods with a high fat content, such as ice cream, chocolate, and cheese, often have lower infection doses. Bacteria can become trapped within hydrophobic lipid molecules, providing a physical barrier to protect cells from being killed by high-acid gastric activity (Matthews, 2006; Montville et al., 2008). Salmonella originating from ice cream has been found to have an infective dose as low as $2.8 \times 10^{1}$, whereas the infective dose of Salmonella originating from most other foods ranges from $10^{1}-10^{7}$ (Montville et al., 2008). Since Salmonella may be excreted in numbers as high as $10^{10}$ per gram of human fecal matter, a small amount of fecal matter carries enough bacteria to infect a large quantity of people (Fan et al., 2009).

Salmonellosis is generally self-limiting, meaning the body works to limit illness through excreting the bacteria. Before infection occurs, the human body has several defenses to prevent infection, including laxoperoxidase, an antibacterial in saliva, high acidity of the stomach, mucoid secretions from intestinal cells, and sloughing of the epithelial cells to prevent attachment (Montville et al., 2008). Once salmonellosis occurs, the human body has immune and diarrheagenic responses to prevent a systemic infection caused by the bacteria (Montville et al., 2008). If the host defenses do not prevent Salmonella from infecting the intestines, then secondary conditions (sequelae) can develop. The major sequelae linked with salmonellosis is reactive arthritis, a condition which 1-2\% of salmonellosis victims will develop (Montville et al., 2008). 


\section{Tomato Biology and Associated Microflora}

A tomato's high water (94.1\%), low carbohydrate (4\%), and low fat (0.3\%) content result in a water activity (Aw) of over 0.98 which allows for most microbes, including bacteria, to survive (Jay, 1992). Of the total dry matter in a tomato, over half of the fruit's contents are glucose and fructose molecules, $10 \%$ are organic acids, $1 \%$ are skin and seeds, and the remaining fractions are alcohols and minerals (Sajur et al., 2007). Tomatoes have a high amount of antioxidants including beta-carotene and xanthophylls, and trace elements including copper, iron, and chromium (Friedman, 2002). These elements cause the fruit to have a high redox potential, which favors the growth of aerobic and facultative anaerobic bacteria (Montville et al., 2008) such as E. coli and Salmonella spp. (Montville et al., 2008).

The phyllosphere environment, the above-ground portion of a tomato plant that includes fruit and leaf surfaces, is viewed as a hostile environment for microbial growth. Conditions such as temperature and moisture change rapidly (Enya et al., 2007a). Traditional microbial colonists of the phyllosphere were thought to originate from soil (namely the rhizosphere), the plant's seed coat, and air movement; water has also been implicated in causing microbial colonization (Matthews, 2006).

With a $\mathrm{pH}$ range of 4.0 to 4.6 , tomatoes are categorized as a high acid product. The low $\mathrm{pH}$ and antibiotic nature of glutamic acid (the principle amino acid in tomato fruit) select for the growth of acid-tolerant microbes such as fungi, yeasts and lactic acidproducing bacteria (Sajur et al., 2007). The predominant bacterial groups found on 
tomatoes are Pseudomonas syringae pv. Tomato, Leuconostoc mesenteroides, and Lactobacillius spp. (Enya et al., 2007a).

In order to understand the microflora of tomato fruit, the changes that tomatoes undergo during their growth and ripening should be addressed. Once flowering is finished, tomatoes take six to seven weeks to reach full size and another 12 days to ripen. During the ripening process, the green pigment chlorophyll is destroyed and lycopene is synthesized in its place (Hayes et al., 1998). As the fruit's pigments undergo degradation and synthesis, various glycoalkaloids are created. These secondary plant metabolites function to protect the plant against pathogens and insects. One such glycoalkaloid, tomatine, has antibiotic properties against pathogenic bacteria such as Escherichia coli, Listeria monocytogenes and Staphylococcus aureus (Friedman, 2002). Green tomatoes contain $500 \mathrm{mg}$ of tomatine per kilogram of fruit. By the time ripening is finished, ripe tomatoes contain only $5 \mathrm{mg}$ tomatine per kilogram. Glycoalkaloids such as tomatine offer protection against pathogens by binding to and disrupting bacterial membranes (Friedman, 2002). Interestingly, tomatine functions best in environments with a $\mathrm{pH}$ greater than 6 , meaning that the acidic surface of a tomato fruit may inhibit the alkaloid's antimicrobial capabilities (Friedman, 2002).

\section{Sources of Contamination on Tomatoes}

Several sources are implicated in contaminating tomatoes with pathogens: soil and crop debris, agricultural water applied to the plant, manure, agricultural workers, and feral animals. S. enterica has been shown to live in fallow soil for up to 6 weeks, with 
populations slowly declining over time (Barak and Liang, 2008). If Salmonella is present in the soil, soil particles may splash up and contaminate tomato fruit growing close to the ground (Barak et al., 2008). Manure is another source of contamination, both from feral and domestic animals allowed to roam the fields and when it is used in agriculture as a fertilizer. Studies have found that $E$. coli can survive up to 21 months in uncomposted sheep manure, and up to 47 days in uncomposted bovine manure (Matthews, 2006). In the United States, fields fertilized with uncomposted manure are required to lay fallow for only 120 days to allow pathogens to die. However, the above study shows that it is possible for pathogens to persist in the soil longer than the required 180 day fallow period (Barak et al., 2008).

Post-harvest contamination can occur throughout the washing and processing steps. It used to be a common practice to place tomatoes in dump tanks filled with cold water as a method of hydro-cooling (to decrease the internal fruit temperature). However, it was reported that Salmonella could be internalized into the tomato using this method (Fonseca, 2006). As the tomato cools, the air within the locules and apoplastic tissures contracts, allowing pathogens to be sucked inside via the stem scar or wounds and cracks on the surface (Fonseca, 2006; Matthews, 2006). Fonseca mentions that internalization into the fruit tissues occurred when Salmonella was in contact with contaminated soil for 10 days (2006). Pathogens may become internalized directly from the soil through the stem scar, and some Salmonella serovars may be able to internalize into the plant system (and subsequently the fruit) through the root (Fan et al., 2009). Internalization is of importance for food safety, because once pathogens become internalized within the fruit, it is difficult for them to be detected and removed through sanitation methods. 
In addition to the postharvest contamination of tomato fruit by food-borne pathogens, water applied to agricultural crops poses another food safety problem. In a study conducted by Barak et al. (2008), fallow soil was irrigated with water containing $S$. enterica and then seeds were planted in the field. Microbiological tests concluded that $S$. enterica was present on the plant leaf phyllosphere for up to 5 weeks. The populations declined each week thereafter (Barak and Liang, 2008). In another experiment, tomato flowers were inoculated with S. enterica, and the resulting tomato fruit was contaminated (Guo et al., 2001). These experiments both demonstrate that contamination to tomatoes does not need to occur only on the surface of the fruit, but it can occur on other plant parts as well (Barak et al., 2008).

A comparison study has not yet been completed on the attachment of S. enterica, E. coli (both 0157:H7and non-0157:H7 strains) and L. monocytogenes to the surface of tomato fruit, however on cantaloupes $S$. enterica had the highest positive and negative surface charges (Matthews, 2006). This resulted in S. enterica being bound to the cantaloupe fruit surface the most tightly (Matthews, 2006). Experimentation testing the attachment of S. enterica serovar Montevideo to tomato fruit provided evidence that the bacteria could survive for long periods of time on the surface, within cracks and the stem scar of the fruit (Matthews 2006).

In order to decrease the food safety risk posed by tomatoes, the microbial quality can be controlled via "sterilization" steps. Antimicrobial agents such as chlorine, hydrogen peroxide, and ozone can be used in an attempt to clean the surface of the tomato by inactivating microbes present (Matthews, 2006). By cleaning the surface of the fruit, pathogens are less likely to enter the flesh upon cutting. One problem with 
attempting to decontaminate tomatoes and other produce is the lack of efficacy of the sanitizers. It has been shown on tomatoes that S. enterica and Erwinia carotovora infiltrate cracks, crevices and intercellular spaces, and the active ingredients in sanitizers are unable to reach microbial cells (Beuchat, 2002).

Time is another important factor in sanitizing produce. The longer bacterial cells are allowed to contaminate tomatoes, the greater chance they have of forming biofilms, a complex polysaccharide matrix that increases their level of attachment to the surface of

the fruit (Danhorn et al., 2007). The high degree of cross-linking forms a dense film with structural integrity and resistance to diffusion. These characteristics make the bacteria imbedded within resistant to both shearing physical forces (such as scrubbing) and chemical sanitizers (Parsek et al., 2000). When cantaloupes were washed with 5\% hydrogen peroxide 30 minutes after contamination, the bacterial count of Salmonella serovar Stanley was decreased by a factor of 3 logs (Fonseca, 2006). However, when washing was done after 24 hours, there was only a 1 log reduction, meaning much of the population remained attached to the fruit surface (Fonseca, 2006). Similar results were reported in tomato fruit (Fonseca, 2006). Additionally, pathogenic bacteria such as $L$. monocytogenes has been found to colonize multispecies biofilms with Pseudomonas fragi and Staphylococcus xylosus (Beuchat, 2002).

\section{Water Quality}

Using sewage and contaminated water for the irrigation of food crops has been associated with the transmission of infectious diseases (Blumenthal et al., 2000). In order 
to prevent such cases of foodborne illness, the World Health Organization (WHO) has created guidelines for global wastewater reuse. However, these guidelines are often difficult to enforce in developing countries, due to the lack of financial resources and infrastructure (Fan et al., 2009). Water for irrigation and pesticide applications should be tested for microbial contamination and disinfected before using, to ensure water quality is being monitored and that the guidelines are respected (Fan et al., 2009). In practice however, agricultural contact water is collected from irrigation canals, ponds, and other contaminated water sources and applied directly to the surface of food crops. Since pathogens attached to the surface of produce are more resistant to inactivation, the water must contain higher levels of chlorine sanitizer. Produce sanitation requires a chlorine concentration of $200 \mathrm{mg} / \mathrm{L}$, whereas only $1-3 \mathrm{mg} / \mathrm{L}$ is needed for drinking water sanitation (Fan et al., 2009).

\section{Groundwater}

Groundwater is considered to have a low risk of fecal contamination due to the natural filtering mechanism of soil. However, groundwater sources are still susceptible to contamination by coliform bacteria and enteric pathogens, meaning that they should be tested for pathogens as often as surface water sources. Variables such as the groundwater depth and soil type can affect the amount of time and filtering that water must undergo to reach the aquifer (Fan et al., 2009). Highly porous soils, such as gravel and sand, are less likely to filter out pathogens, since the larger pore size allows particulates to remain in the water and does not slow down percolation (Sylvia et al., 2005). Other factors such as 
the amount of rainfall, construction of an unprotected well, and proximity of a septic tank leach field also play a role in groundwater contamination (Fan et al., 2009). Studies have shown that particular pathogens, such as E. coli 0157:H7, are able to persist below the soil surface for up to 2 months after application. Such evidence shows that once contaminated, enteric pathogens in the soil may be diluted and persist within the groundwater (Fan et al., 2009).

\section{Surface water}

Due to the nature of the water source, surface water is more susceptible to contamination. Open, unprotected water has an increased risk of receiving direct discharge of fecal matter from wild animals and domestic livestock (Fan et al., 2009). Higher pathogen loading occurs after major rainfall events, such as when untreated manure runs off into the water source (Fan et al., 2009). The survival of enteric pathogens in water depends on four major factors: temperature of the water, sunlight, particulates, and the amount of soluble organic matter (Fan et al., 2009). Pathogens survive for longer periods of time at lower temperatures. Studies of surface water contaminated with manure containing E. coli $0157: \mathrm{H} 7$ showed that the pathogen survived for 92 days at ambient temperature (Fan et al., 2009). Bacteria survive for longer periods of time in the dark, where there are lower amounts of ultraviolet (UV) light (Sylvia et al., 2005). The amount of particulate matter in the water source is an important factor, because it protects pathogens against sunlight and antimicrobials. For this reason, enteric pathogens are most likely to be found in pond sediments, where they attach to particles and settle out from 
the water (Fan et al., 2009). Lastly, the presence of large amounts of soluble organic matter can result in the pathogen persisting for longer amounts of time. As heterotrophic organisms, coliform bacteria rely on organic matter as a carbon source. Soluble organic matter in water provides a rich carbon source for the bacteria to make use of (Fan et al., 2009; Sylvia et al., 2005).

Similar to sanitizing fruit, water can also be sanitized via several means including chlorination, UV light, ozone, and the addition of heavy metals. Copper is one antimicrobial used in agricultural production (Epstein et al., 2001). As a micronutrient, heavy metals such as copper are used in biochemical pathways as an enzyme cofactor to promote growth (Epstein et al., 2001; Sengor et al., 2009). However, at higher concentrations, copper is a biocide used on agricultural crops such as pear, walnut, peach, and apple trees, as well as bodies of water. Inorganic forms, such as copper sulfate and copper hydroxide, are used as broad-spectrum fungicides, algaecides and bacteriocides, since bacteria, fungi, and mollusks have the highest sensitivity to metal toxicity (Epstein et al., 2001). Growth inhibition can occur in three ways. When coupled onto a microbial membrane, copper can cause it to lose integrity and break. If the metal ions are absorbed into the cytoplasm, they will oxidize enzymes, thereby inactivating organelles. Lastly, ions can directly react with DNA, causing it to deactivate (Sengor et al., 2009). These three mechanisms cause longer lag times in the population growth kinetics of bacteria, thereby reducing the growth rate (Sengor et al., 2009). An interplay of $\mathrm{pH}$, organic matter levels, and clay content can vary the toxic concentrations in soils. Studies show that soils amended with $50 \mathrm{mg} \mathrm{Cu} \mathrm{kg}^{-1}$ had a reduced rate of soil respiration (Epstein et al., 2001). 


\section{Fecal Indicator Organisms}

Fecal indicator organisms (FIOs) are non-pathogenic organisms used in monitoring the infection risk that foods or environments pose for humans (Oliver et al., 2009; UC, 2007). Regulatory organizations often use FIOs instead of actual pathogenic organisms for monitoring the microbial quality of water and agricultural commodities due to their cost effectiveness, increased timeliness, and ease of monitoring in the field and in laboratories (Blumenthal et al., 2000; Oliver et al., 2009). In order to be an indicator of fecal contamination, the organism needs to be consistently and universally present in feces and easily tested for (Fan et al., 2009; Tallon et al., 2005). According to the World Health Organization (WHO), other criteria that FIOs must exhibit include not having the ability to multiply in natural waters, as well as persisting in water and responding to treatment in a manner similar to fecal pathogen (Tallon et al., 2005). The last two criteria are important for indicator organisms, since they are not only used to demonstrate the presence of pathogenic organisms (as index organisms do), but also to measure the effectiveness of the treatment processes, such as disinfection (Blumenthal et al., 2000). A diagram of several bacterial fecal indicator organisms can be found in Figure 1-1.

\section{Enterobacteriaceae and total coliforms}

One such indicator of contamination in post-harvest processes is Enterobacteriaceae, a family of Gram-negative bacteria. (Paulsen et al., 2007). 
Enterobacteriaceae are non-spore forming facultative anaerobes, which ferment lactose into lactic acid and gas at $35^{\circ} \mathrm{C}$ within $48 \mathrm{hrs}$. Also commonly used as a FIO are total coliforms. Members of the Enterobacteriaceae family, total coliforms are $\beta$-galactosidase positive. The coliform group contains bacteria of the genus Escherichia, Citrobacter, Enterobacter, and Klebsiella (Fan et al., 2009). Although total coliforms were widely used, they were shown to be unreliable indicators of fecal contamination because they are capable of growing in the external environment and in water systems (Tallon et al., 2005). In a study isolating over 1000 coliform strains sampled from several types of water, it was found that $61 \%$ of coliforms were non-fecal, thus showing that total coliforms are not a reliable indicator of fecal contamination. Especially if water sources contain large concentrations of organic matter, coliforms may increase in numbers (Fan et al., 2009). Instead of using total coliforms as FIOs, they are now being used to monitor changes in water quality (Tallon et al., 2005).

\section{Fecal coliforms}

Fecal (or thermotolerant) coliforms are a subset of coliforms that produce gas when incubated at a temperature of $44.5 \pm 0.2^{\circ} \mathrm{C}$ for $24 \pm 2 \mathrm{~h}$. The higher temperatures were thought to select for coliform bacteria of fecal origin (Tallon et al., 2005). Fecal coliforms are used as an indicator organism to monitor drinking and recreational water quality by the United States Environmental Protection Agency (EPA) and, therefore, by the Tomato Producers Association (Gombas, 2008). Depending on the environmental conditions, fecal coliforms may not be specific enough to provide an effective indication 
of fecal pollution in drinking water (Alonso et al., 1999). Klebsiella, Enterobacter, and Citrobacter spp. (the KEC coliforms) are the major genera of $\beta$-galactosidase positive thermotolerant coliforms that are not E. coli. Due to the occurrence of the environmental KEC coliforms that do not have fecal origins, the term "thermotolerant coliform" is considered more appropriate than "fecal coliform". A survey of over 50 environmental water samples in Valencia, Spain found that between $72 \%$ and $82.7 \%$ of the thermotolerant colonies within the samples were KEC coliforms with fecal origins. The remaining colonies were $E$. coli and thermotolerant coliforms with non-fecal origins (Alonso et al., 1999).

E. coli

Of the fecal indicator organisms used, E. coli is considered the most reliable FIO (Alonso et al., 1999; Tallon et al., 2005). E. coli is a species within the thermotolerant coliforms group, and is distinguished by its ability to produce indole from tryptophan. $E$. coli differs from the KEC coliforms because it synthesizes the enzyme $\beta$-glucoronidase. As an indigenous member of the intestinal flora in warm-blooded animals, E. coli was introduced as a FIO because it is the only coliform specific to fecal contamination. Unlike the KEC coliforms, E. coli is not considered to be an environmental organism as it cannot grow in non-polluted river water (Tallon et al., 2005). Corresponding with the WHO criterion that the indicator organism should represent a majority of the thermotolerant organisms in feces, E. coli represent over $94 \%$ of the thermotolerant 
coliforms in human feces. It should be noted that although $E$. coli is considered the best bacterial FIO, it is not a suitable indicator organism of viruses (Tallon et al., 2005).

\section{Microbial water standards}

Regulatory organizations, such as the World Health Organization (WHO) and US Environmental Protection Agency (EPA) use the aforementioned fecal indicator organisms as a basis for their microbial water quality standards (Blumenthal et al., 2000). Standards are often based upon how the water will be used. For example, WHO guidelines suggest that water used for unrestricted irrigation (water applied to crops likely to be eaten uncooked) and flood irrigation have a geometric mean of less than 1,000 colony forming units (CFUs) of fecal coliforms per $100 \mathrm{ml}$ (Blumenthal et al., 2000). However, water applied to restricted crops (those that will be cooked) may have a geometric mean up to $100,000 \mathrm{CFUs}$ of fecal coliforms per $100 \mathrm{ml}$ (Blumenthal et al., 2000; Matthews, 2006). The United Fresh Produce Association published a set of food safety guidelines for the tomato industry, with water standards based upon the EPA's regulations (EPA, 2002, 2008; Gombas, 2008). The tomato guidance document uses $E$. coli as an indicator for fecal contamination. Plants irrigated with non-foliar techniques (such as trickle irrigation, in which water does not contact the fruit), must follow the EPA's freshwater recreational standards, which allow for a geometric mean of no more than 126 CFU E. coli per $100 \mathrm{ml}$ (EPA, 2002, 2008; Gombas, 2008). Foliar irrigation, in which the fruit is at higher risk for contamination due to its direct contact with irrigation 
water, must follow the EPA's potable water standards: 0s of CFU E. coli per $100 \mathrm{ml}$ (EPA, 2002; Gombas, 2008).

Microbial water guidelines in Canada use more than one indicator organism. The Canadian Water Quality Guidelines for the Protection of Agricultural Water Uses recommends a maximum of 1,000 CFUs total coliforms per $100 \mathrm{ml}$. Fecal coliforms have a recommended standard of one-tenth that of total coliforms, 100 CFUs fecal coliforms per $100 \mathrm{ml}$ irrigation water (Matthews, 2006). This would be a result of the increased specificity of fecal coliforms, and the decreased prevalence as environmental organisms. The Ministry of Water, Land and Air Protection sector of the British Columbian government set guidelines for crops eaten raw, based upon fecal coliforms and E. coli. Geometric means of fecal coliforms should be less than 200 CFUs per $100 \mathrm{ml}$, and geometric means of $E$. coli should not exceed 77 CFUs per $100 \mathrm{ml}$ (Matthews, 2006). Similar to the above regulations, the lower number of $E$. coli allowed in irrigation waters points to the increased specificity and increased prevalence of pathogenic organisms in the E. coli species as compared to fecal coliforms as an indicator organism.

\section{$\underline{\text { Use of Petrifilms }}$}

Petrifilms (3M, St. Paul, Minn., USA) were originally produced as a culture-based bacterial analysis method for food items, though their usage has spread to water quality testing as well (Pearson et al., 2008). Petrifilms are an industry-recognized means of quantifying various fecal indicator organisms, and are validated by the Association of

Official Analytical Chemists (AOAC) and the Association French Normalization 
Organization Regulation (AFNOR). Petrifilms serve as alternative means to using International Organization Standards (ISO) culture-based methodologies, utilized for their high selectivity, ease-of-use, and cost effectiveness (Paulsen et al., 2007). Studies comparing Enterobacteriaceae petrifilms to violet red bile glucose, the ISO method for enumerating Enterobacteriaceae, found that the petrifilms tended to yield higher numbers, although these differences were not significant (Blood et al., 1995; Paulsen et al., 2007).

Enterobacteriaceae petrifilms are composed of dehydrated MacConkey-based media on flexible foils, making them alternatives to other culture methods. The media contains a cold water-soluble gelling agent, bile salts as a selectivity ingredient for Enterobacteriaceae, and violet red to suppress gram-positive bacteria (Paulsen et al., 2007). Enumeration of red Enterobacteriaceae colonies occurs due to the presence of triphenyl tetrazoliumchloride (TTC), and the conversion of glucose to acid forms a yellow halo around the colony (Marks, 2005; Paulsen et al., 2007). Additionally, gas bubbles trapped by the top film layer also serve in identifying colonies of Enterobacteriaceae (Paulsen et al., 2007). Coliform count petrifilms, used to enumerate total coliforms and fecal coliforms (when incubated at a higher temperature), contain a media composed of similar elements: bile salts, violet red, a TTC indicator to turn the colonies red, and a $\mathrm{pH}$ indicator (3M). As coliform colonies produce lactic acid, the $\mathrm{pH}$ indicator turns the gel a deeper color, resulting in deep pink rings around coliform colonies (3M). In addition to the constituents in Coliform count petrifilms, the media in E. coli petrifilms contains 5-bromo-4-chloro-3-indolyl-beta-D-glucoronide (BCIG). When cleaved by beta-glucoronidase, an enzyme that only E. coli produces (Anonymous, 
2000) a blue precipitate is formed which results in a blue E. coli colony, making it easy for enumeration (Anonymous, 2000).

\section{Good Agricultural Practices on Tomatoes}

Since there are so many factors in enhancing food safety, it has been suggested that an important control measure to prevent the contamination of fresh tomatoes is by practicing Good Agricultural Practices (GAPs). GAPs, a series of guidelines and intervention strategies being implemented on farms to reduce microbial hazards, were developed to decrease the number of food safety risks and hazards that may be amplified due to agricultural practices. The Food and Drug Administration (FDA) released the Guide to Minimize Microbial Food Safety Hazards for Fresh Fruits and Vegetables, a manual for the agricultural industry that summarizes a series of guidelines for GAPs (Fan et al., 2009; Food Safety Initiative Staff 1998). The FDA guide addresses the major aspects of food safety on the farm: water quality, manure and compost applied to the soil, cleaning and sanitation, health and hygiene of agricultural workers, animal and pest management, and traceback strategies that allow produce recalls to occur (Food Safety Initiative Staff 1998). These practices involve using agricultural strategies that are shown to reduce risk of contamination by pathogens. Included is testing irrigation water for $E$. coli or Salmonella before applying it to tomato crops and limiting the access that migratory birds and feral animals have to the produce (especially ruminants, which are reservoirs for E. coli 0157:H7 (Food Safety Initiative Staff 1998). Additional practices include educating farm workers to sanitize themselves and tools properly, so potential contamination is not spread out among the tomato crop. These practices serve as a 
preventative measure, since it is not possible to sufficiently sanitize fresh produce before consumption (Fonseca, 2006).

There are currently few governmental regulations enforcing the implementation of GAPs in agricultural production systems - the guidelines are buyer-regulated. Produce suppliers, especially those selling their produce through school systems, supermarkets and exportation are often required to have GAPs audits performed by the USDA or thirdparty companies. These audits are intended to ensure that crops are being grown in accordance with GAPs (Fan et al., 2009). In 2008, the United Fresh Produce Association published science-based guidelines for fresh and fresh-cut tomatoes. The tomato guidance document addresses tomato GAPs, including water quality metrics and tomato production standards, in a manner similar to how the USDA GAPs audits are addressed (Gombas, 2008).

\section{$\underline{\text { Research Rationale }}$}

The goal of this field and laboratory study was to address the following questions:

1) Do increases in bacterial loads of agricultural contact water correspond to increases in bacterial loads on tomato fruit?

2) What is the relative value of using Enterobacteriaceae, total coliforms, fecal coliforms, and E. coli as potential indicator organisms?

3) Does the amount of fecal indicator organisms present in surface water differ over the course of the growing season (June - September)? 
4) What environmental factors play a significant role in the quantitative differences of indicator organisms between different surface water sources?

5) What is the value of using Enterobacteriaceae, total coliforms, fecal coliforms, and E. coli as indicator organisms? How tightly are the counts of each correlated?

6) Does the application of a copper sulfate treatment to a surface pond affect the bacterial load of indicator organisms in the pondwater? 


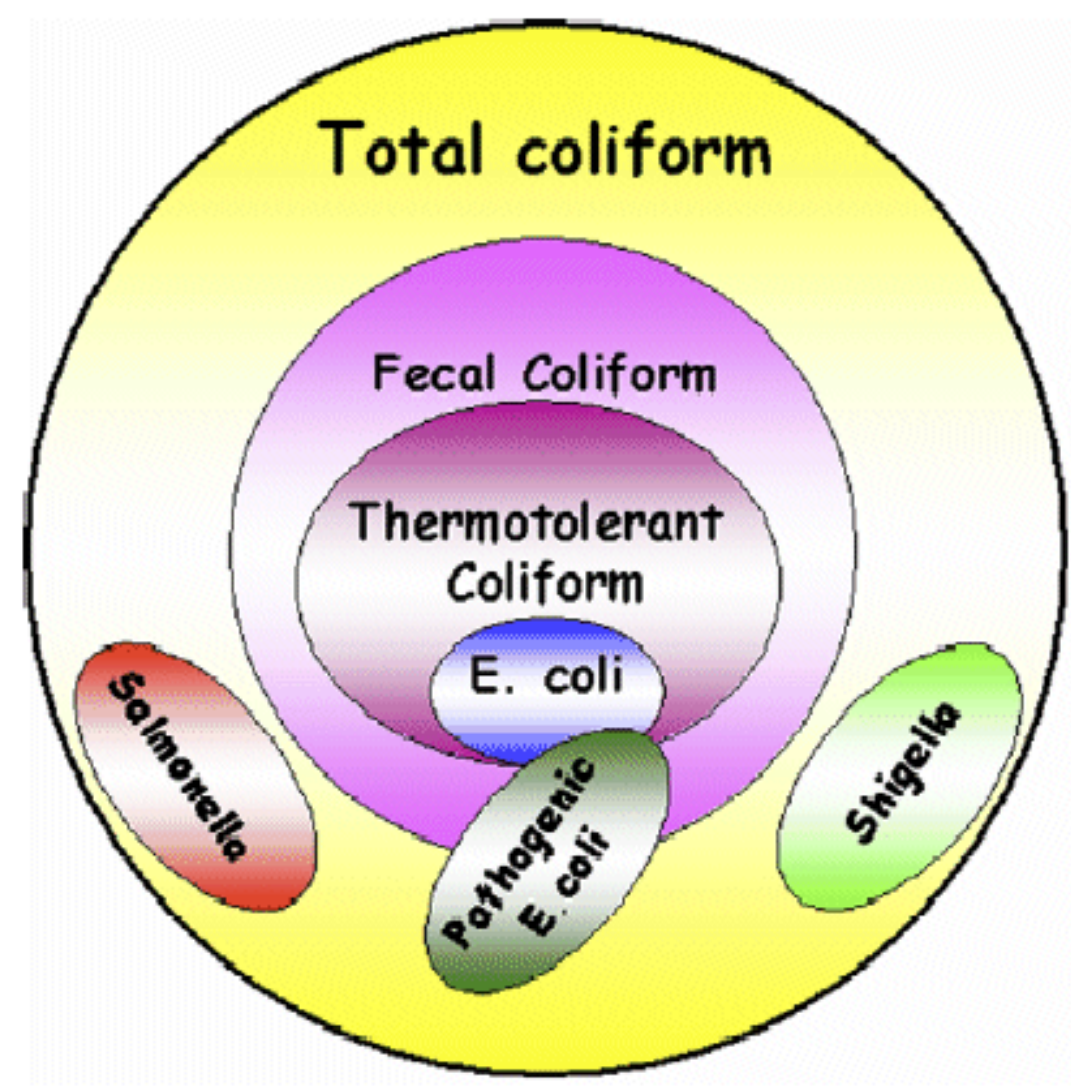

Figure 1-1. A visualization of the relationship between various fecal indicator organisms and three genera of pathogenic bacteria that cause food-borne illness. In this study, Enterobacteriaceae, total coliforms, fecal coliforms, and E. coli were used as fecal indicator organisms. Reproduced from: University of California, 2007. 
Table 1-1. List of outbreaks associated with enteric human pathogens and tomatoes, 1990 to 2006.

\begin{tabular}{ccccc}
\hline Pathogen & Month-Year & Location & Number Ill & Source Region \\
\hline S. Javiana & June-Aug 1990 & IL, MI, MN, WI & 176 & SC \\
S. Montevideo & June-Aug 1993 & IL, MI, MN, WI & 100 & SC \\
S. Baildon & Dec 1998 - Jan 1999 & Multi & 86 & FL \\
Shigella flexneri & May 2001 & NY & 886 & FL \\
S. Javiana* & June-July 2002 & FL & 141 & Unknown \\
S. Newport & Sept-Oct 2002 & Multi & 510 & VA \\
S. Braenderup & July 2004 & Multi & 125 & FL \\
S. Javiana and other & July 2004 & Multi & 429 & VA \\
serovars & & & & FL \\
S. Newport & July-Nov 2005 & Multi & 72 & Unknown \\
S. Braenderup* & Nov-Dec 2005 & Multi & 82 & OH \\
S. Newport & July- Nov 2006 & Multi & 115 & 190 \\
S. Typhimurium & Sept-Oct 2006 & Multi & & \\
\hline
\end{tabular}

*On prediced tomatoes

Source: Fan, Niemira et al. 2009.

$\wedge$ On presliced tomatoes 


\section{Chapter 2 : Comparing Source of Agricultural Contact Water and the Presence of Fecal Indicator Organisms on the Surface of 'Juliet' Grape Tomatoes}

\section{Chapter Abstract}

Tomatoes (Solanum lycopersicum) have been implicated as the cause of several foodborne illness outbreaks in the United States, most notably in cases of salmonellosis. Sources of biological contamination include agricultural workers, feral animals, manure, and water. Although microbial water quality standards exist for agricultural use, little is known about how the levels of the fecal indicator organisms in water relate to the counts on the tomato fruit surface. This study used four types of fecal indicator organisms commonly used in microbial water quality standards (Enterobacteriaceae, total coliforms, fecal coliforms, and E. coli) to monitor the water quality of two surface ponds and a groundwater source and the phyllosphere of treated grape tomatoes over the 2009 and 2010 growing seasons. Source and date caused a significant difference in the counts of fecal indicator organisms, with groundwater having significantly lower counts of all fecal indicator organisms than the two surface water sources. Considerable variability in bacterial counts was found in the surface water sources over the course of the season, partially explained by environmental variables such as water temperature, $\mathrm{pH}$, precipitation, and air temperature. The microbial counts on the surfaces of the tomato fruit did not reflect the water treatments applied to the plants: only certain indicator organisms had a significant difference among treatments, with results differing between the two sampling seasons. These results justify the need for various and frequent water quality tests on agricultural contact water. 


\section{Introduction}

The number of food-borne illness outbreaks resulting from fresh fruits and vegetables has increased in recent years, so that fresh produce now accounts for $29 \%$ of food-borne outbreaks (Beuchat, 2002). This is due in part to the increase in produce consumption, the source of consumed produce, and year-round availability (Beuchat, 2002; Putnam et al., 1999). Tomatoes in particular have had an increase in consumption in the United States, and between 1996 and 2008 tomatoes were alone responsible for $17.1 \%$ of produce outbreaks (Beuchat, 2002). Since tomatoes are often eaten raw, there is no inactivation step to kill microbes before consumption (Matthews, 2006).

Several sources are implicated in contaminating tomatoes with pathogens including manure, feral animals, and agricultural contact water for irrigation and pesticide applications (Fan et al., 2009). Despite knowledge that the use of contaminated water for irrigation or pesticide application on food crops has been associated with the transmission of foodborne pathogens, this water is still used in agriculture today (Fan et al., 2009). Microbial water standards are published by the World Health Organization (WHO) for wastewater reuse in agriculture, and by the United Fresh Produce Association (UFPA) for agricultural water use on tomatoes (Blumenthal et al., 2000; Gombas, 2008). Water standards such as these are being incorporated into Good Agricultural Practices (GAPS), a series of guidelines implemented in agriculture to reduce microbial hazards (Fan et al., 2009; Food Safety Initiative Staff 1998). Although microbial water standards exist, little scientific data is available on how high microbial counts in water effect the microbial counts on the tomato phyllosphere, and thus how effective these standards are at preventing foodborne illnesses. 
Regulatory organizations such as the World Health Organization and the United States Environmental Protection Agency use fecal indicator organisms to monitor the infection risk that water or foods pose for humans (Oliver et al., 2009). Fecal indicator organisms are used instead of actual pathogenic organisms due to their cost effectiveness, increased timeliness, and ease of monitoring in the field and in laboratories (Blumenthal et al., 2000). In order to be a fecal indicator organism, the organism needs to be consistently and universally present in feces, as well as not be able to multiply in natural waters (Blumenthal et al., 2000; Fan et al., 2009; Tallon et al., 2005).

The fecal indicator organisms used to monitor water quality in this study were Enterobacteriaceae, total coliforms, fecal coliforms, and E. coli. Enterobacteraceae are a family of gram-negative facultative anaerobes (Paulsen et al., 2007). Total coliforms are a subset of Enterobacteriaceae, and include bacteria from the genus Escherichia, Citrobacter, Enterobacter, Klebsiella, and Salmonella (Fan et al., 2009). Although total coliforms are used for microbial quality, they are unreliable indicators of fecal contamination because they are capable of growing in the environment and in water systems (Tallon et al., 2005). In a study isolating over 1000 coliform strains sampled from several types of water, it was found that $61 \%$ of coliforms were of non-fecal origin. Especially if a water source contains large concentrations of organic matter, coliforms may increase in numbers (Fan et al., 2009).

Fecal, or thermotolerant, coliforms are a subset of total coliforms that produce gas when incubated at a temperature of $44.5^{\circ} \mathrm{C}$, higher than the incubation temperature to determine total coliforms. Fecal coliforms are used as an indicator organism by the World Health Organization (WHO) for their standards for agricultural use of reclaimed wastewater (Blumenthal et al., 2000). Similar to the above fecal indicator organisms, certain fecal coliforms will reproduce in 
environmental conditions without a fecal origin (Alonso et al., 1999). When using water standards based upon quantitative results, environmental amplification can lead to false conclusions on the microbial water quality.

Of the fecal indicator organisms used, E. coli is considered to be the most reliable fecal indicator organism (Alonso et al., 1999; Tallon et al., 2005). As an indigenous member of the intestinal flora in warm-blooded animals, E. coli is specific to fecal contamination. Thus, it cannot grow in non-contaminated river water (Tallon et al., 2005). The microbial water standards used by the United Fresh Produce Company and the US Environmental Protection Agency are based upon the presence and levels of $E$. coli in water for agricultural and recreational usage (EPA, 2002, 2008; Gombas, 2008).

Petrifilms serve as an alternative means to using ISO culture-based methodologies and are an industry-recognized means of measuring indicator organisms (Paulsen et al., 2007). Composed of dehydrated MacConkey-based media on disposable foils, the media in Petrifilms contains a cold water-soluble gelling agent, bile salts to select for Enterobacteriaceae, and violet red to suppress gram-positive bacteria (Paulsen et al., 2007). The inclusion of additional indicators in the media (determined by the type of Petrifilm) facilitate the enumeration of the organisms (3M, 2006a, 2006b, 2006c; Anonymous, 2000; Paulsen et al., 2007).

To the best of our knowledge, there is little scientific information addressing the effect of microbial water quality on the presence and quantity of fecal indicator organisms on the tomato fruit surface. This information is essential to determine the validity of microbial standards for water to be used in tomato production. In this study the level of several fecal indicator organisms in three water sources (two ponds and one groundwater source) were compared to the 
number of indicator organisms on the surfaces of grape tomatoes treated with the above sources. Water samples were taken and tested frequently during the sampling seasons to determine the influence of seasonality and various environmental variables on the counts of fecal indicator organisms. To determine the effect of microbial water quality on the surface of grape tomato fruit, water from the three water sources was used in pesticide applications on the tomato plants. Tomato samples were harvested and washed, and washwater was plated on Petrifilms for bacterial enumeration. Results among different fecal indicator organisms were also compared to determine the value of using Enterobacteriaceae, total coliforms, fecal coliforms, and E. coli as fecal indicator organisms.

\section{Materials and Methods}

Field Design. Field studies for 2009 and 2010 were completed at the University of Maryland's Wye Research and Education Center (WREC) in Queenstown, Maryland (38 56', $\left.76^{\circ} 07^{\prime}\right)$. The soil at the site was classified as a Nassawango silt loam (fine-silty, mixed, semiactive, mesic, Typic Hapludult). Plots were arranged in a randomized complete block design with 5 blocks along a moisture gradient (Appendix A); each block was spaced $30 \mathrm{ft}(9.1 \mathrm{~m})$ from the next and contained three experimental units located $30 \mathrm{ft}(9.1 \mathrm{~m})$ apart. During the 2009 growing season, each of the experimental units was comprised of paired rows located $6 \mathrm{ft}(1.8 \mathrm{~m})$

apart. Each row contained one tomato cultivar: a regular shipping cultivar ('Mountain Pride') or a grape tomato cultivar ('Juliet'). Only the grape tomatoes were used in this study. In 2010, the experimental units were re-randomized under the same block design and each treatment plot contained only one row of five 'Juliet' grape tomato plants, with an in-row spacing of $2 \mathrm{ft}(0.61$ 
m) (Appendix A). In 2009 and 2010 the greenhouse grown transplants were planted on June 10 and June 2 (Julian days 161 and 153), respectively. Plants were grown on black agricultural plastic mulch and trained with a four-string stake system, similar to DelMarVa's common tomato production practices. When needed, the field plot was trickle irrigated and fertigated using well water.

The tomato field was placed on a 7 to 14 day conventional spray schedule. Water was sampled from the same three water sources used for the pesticide treatments applied to the field plot: a groundwater (well) source (W-G), a surface pond (W-S), and a pond that was treated with copper sulfate (Cutrine Ultra) (W-CS) as an algaecide on August 25, 2009 (Julian day 237) and June 4, 2010 (Julian day 155). Water from each of these sources was mixed separately with standard agricultural chemicals (Appendix $\mathrm{C}$ ) and applied to plots with a $\mathrm{CO}_{2}$-pressurized boom sprayer (Appendix B). Each treatment was applied with a separate sprayer manifold consisting of nozzles, hoses, and a tank. In 2009, the spray treatments were applied on July 2, July 14, July 28 , August 9, August 20, August 30, and September 10. In 2010, the spray treatments were applied on July 26, August 8, August 22, August 30, and September 7. The pesticide treatments for the 2010 season were applied one day before sampling.

Water Sampling. In 2009, $50 \mathrm{ml}$ water samples were collected in disposable centrifuge tubes (Corning Incorporated, Corning, NY) on a biweekly basis from June 4 to July 20. From then on sampling occurred weekly until September 21 (with the exception of August 2). At each sampling date in 2009 , one sample of surface water was collected aseptically at three locations around each of the ponds. On August 17, 2009, repetitions were added for the water samples, one repetition was taken at each of three points around the pond. 
Sampling during the 2010 season occurred biweekly from June 2 to July 19, and weekly from July 27 to September 15 . Three replications of surface water samples were taken at the site of water collection for agricultural contact water. Before sampling at each location in the two surface water sources, water was agitated at each location with efforts made to minimize disruption to the silt. Water temperature and $\mathrm{pH}$ were recorded at each sampling site using a handheld pH/ORP meter, model HI98121 (Hanna Instruments, Woonsocket, RI). At each sampling date during the two field seasons, three well water samples were taken from a faucet located within the chemical preparation room.

During the 2010 sampling season, samples of each water source were taken directly from the sprayer, termed "spray catches". Three samples of each source were taken on July 27, August 10, August 23, and September 8, 2010. After filling the appropriate 3-gallon canister to capacity with treatment water, water was run through the spray manifold before sampling. Spray catch samples were collected directly from one of five nozzles (the other four nozzles were covered), before pesticides were added to the canisters. The canisters and spray manifolds were rinsed out with sample water and stored with lids until the next use.

Sampling. Aseptic sampling of ripe fruit occurred at seven dates in 2009, weekly from July 20 (Julian day 200) to September 14 (Julian day 256), and at six dates in 2010, weekly from July 28 (Julian day 208) to September 8 (Julian day 251). During the 2009 sampling year all tomatoes were harvested ripe (with the exception of July 20, in which tomato samples were picked green). During the 2010 sampling year, all sampling dates consisted of a sample of ripe tomatoes. Additionally, unripe tomato samples were taken on July 20, 2009, July 28, 2010 and August 16, 2010, to quantify the effect of maturity level on bacterial load. 
A sample consisted of six tomatoes (calyx intact) cut with ethanol-sterilized scissors from various locations on the plants and aseptically placed into a Whirl-pak® bag. Between each sample, scissors were disinfected with ethanol. To prevent contamination, gloves were changed between replicates and the tomatoes were never touched with gloves directly (they were handled only within the bag). Once harvested, the samples were kept at $5^{\circ} \mathrm{C}$ for a maximum of four hours, until they could be weighed and processed in the laboratory. Grape tomato phyllosphere washes were recovered by adding $100 \mathrm{ml}$ of sterile water (in 2009) or phosphate-buffered saline (PBS, in 2010) to each tomato sample. Each sample was then carefully massaged until the entire surface of each tomato, including under the calyx, was thoroughly wetted (for approximately 1 minute).

\section{Enumeration of Enterobacteriaceae, Total Coliforms, Fecal Coliforms and E. coli.}

$3 \mathrm{M}$ petrifilms ${ }^{\circledR}(3 \mathrm{M}$, St. Paul, MN) were used to quantify the number of colony-forming units (CFU) of Enterobacteriaceae, total coliforms, fecal coliforms, and E. coli on the phyllosphere of tomato fruit. A one ml aliquot from each serial dilution (ranging from $10^{0}$ to $10^{-3}$ ) of phyllosphere washwater was plated onto each of the Enterobacteriaceae and total coliform petrifilms, which were then incubated for $24 \pm 2$ hours at $38 \pm 1^{\circ} \mathrm{C}$. Fecal (thermotolerant) coliforms were enumerated by plating $1.0 \mathrm{ml}$ of washwater on total coliform petrifilms, and incubating for $24 \pm 2$ hours at $44 \pm 1^{\circ} \mathrm{C}$. In the 2010 sampling season, E. coli were enumerated by plating $1.0 \mathrm{ml}$ of washwater on $E$. coli petrifilms, and incubating for $48 \pm 2 \mathrm{hrs}$ at $38 \pm 1^{\circ} \mathrm{C}$. Serial dilutions of water samples $\left(10^{0}-10^{-2}\right)$ were plated in the same manner as the phyllosphere washes. After incubation, petrifilms were counted using a stereomicroscope, per the manufacturer's instructions (3M, 2006a). If petrifilms could not be counted immediately after removal from the incubator, they were placed in a freezer at $-20^{\circ} \mathrm{C}$ until they could be 
enumerated. The final colony counts were calculated from the number of colonies found on Petrifilms with 30 to 300 colonies, which was then multiplied by the dilution factor. These values were then multiplied by 100 to standardize the counts to CFU / $100 \mathrm{ml}$. After standardization, 0.1 was added to each of the counts as a second standardization method so that $\log$ transformation could occur before statistical analysis.

Enrichment and qualification of Salmonella spp. RapidChek® Salmonella Test Kit (Strategic Diagnostics Inc., Newark, DE) was used to test for Salmonella spp. in water and phyllosphere samples. Samples were processed according to manufacturer's instructions (RapidChek, 2010). Equal volumes of each phyllosphere wash and water treatment replicates were pooled into a single $25 \mathrm{ml}$ sample for each treatment. Each sample was incubated in $225 \mathrm{ml}$ RapidChek® Salmonella enrichment media at $42^{\circ} \mathrm{C}$ for about 18 hours. One milliliter of each enriched sample was then added to $10 \mathrm{ml}$ of prepared tetrathionate broth, a selective media for Salmonella, prewarmed to $42^{\circ} \mathrm{C}$. After incubation at $42^{\circ} \mathrm{C}$ for 24 hours, $1.0 \mathrm{ml}$ aliquots of each solution were transferred to test tubes where a test strip was inserted. After 10 minutes, the test strip was checked for results per manufacturer's instructions (RapidChek, 2010).

Statistical analysis. Enterobacteriaceae, total coliforms, fecal coliforms, and E. coli counts from the water samples and tomato phyllosphere were log transformed prior to statistical analysis. An analysis of variance (ANOVA) was performed using PROC MIXED procedure of the statistical analysis systems program version 9.2 (SAS institute, Cary, NC, USA) to determine the effect of sampling date and treatment on bacterial counts. Environmental variables were analyzed using the stepwise regression procedure (PROC REG) to determine the relationships between maximum air temperature, $\mathrm{pH}$, water temperature, date, and precipitation on bacterial levels in water samples. 


\section{Results}

\section{Seasonality of microbial water quality.}

Source and date effect.

Samples from the three different water sources showed significant differences in counts of Enterobacteriaceae, total coliforms, and fecal coliforms, the result of a significant effect by source, date, and an interaction between the two main effects (2009 data: Fig. 2-1 to 2-3, 2010 data: Fig 2-4 to 2-7). Although a significant interaction occurred between source and date, there were clear trends in the bacterial counts over the course of the 2009 and 2010 sampling seasons. In both seasons, the log-transformed counts of the fecal indicator organisms on the groundwater samples (W-G) evaluated were always negative, representing colony counts of $0 \mathrm{CFU} / 100 \mathrm{ml}$. The W-G colony counts did not vary throughout the season and samples were significantly lower than the pond water (W-S) and copper-sulfate treated pond water (W-CS) samples (Fig. 2-1 to 27). The levels of Enterobacteriacaeae and total coliforms in the W-S and W-CS samples did not differ significantly (Figs. 2-1; 2-2; 2-4 and 2-5). In 2009, the counts of fecal coliforms in the WS and W-CS samples were not significantly different (Fig. 2-3). In 2010, the counts of fecal coliforms exhibited greater fluctuations over the course of the season (Fig. 2-6). At Julian day 208 and 228, W-S samples had significantly lower counts than W-CS samples. The E. coli counts showed significant variation over both source and date, with W-S ranging from -1.00 log CFU/100 ml to $3 \log$ CFU/100 ml, and W-CS ranging from -1.00 log CFU/100 ml to about 2.5 $\log$ CFU/100 ml (Fig. 2-7).

In 2009, the counts of Enterobacteriaceae fluctuated between 3.11 and $5.11 \log$ CFU/100 $\mathrm{ml}$ over the sampling season for W-CS and between 3.27 and $4.29 \log$ CFU/100 $\mathrm{ml}$ for W-S (Figure 2-1). Counts of total coliforms fluctuated between 2.30 and $4.47 \log$ CFU/100 $\mathrm{ml}$ for W- 
$\mathrm{CS}$ and between 2.60 and $4.08 \mathrm{log} \mathrm{CFU} / 100 \mathrm{ml}$ in W-S (Fig. 2-2). As seen in Figure 2-3, the counts of fecal coliforms were lower than the total coliform and Enterobacteriaceae counts.

Levels in W-CS fluctuated between -1.00 and $3.58 \log$ CFU/100 ml, and W-S fluctuated between 2.00 and $3.77 \log$ CFU/100ml (Fig. 2-3). 


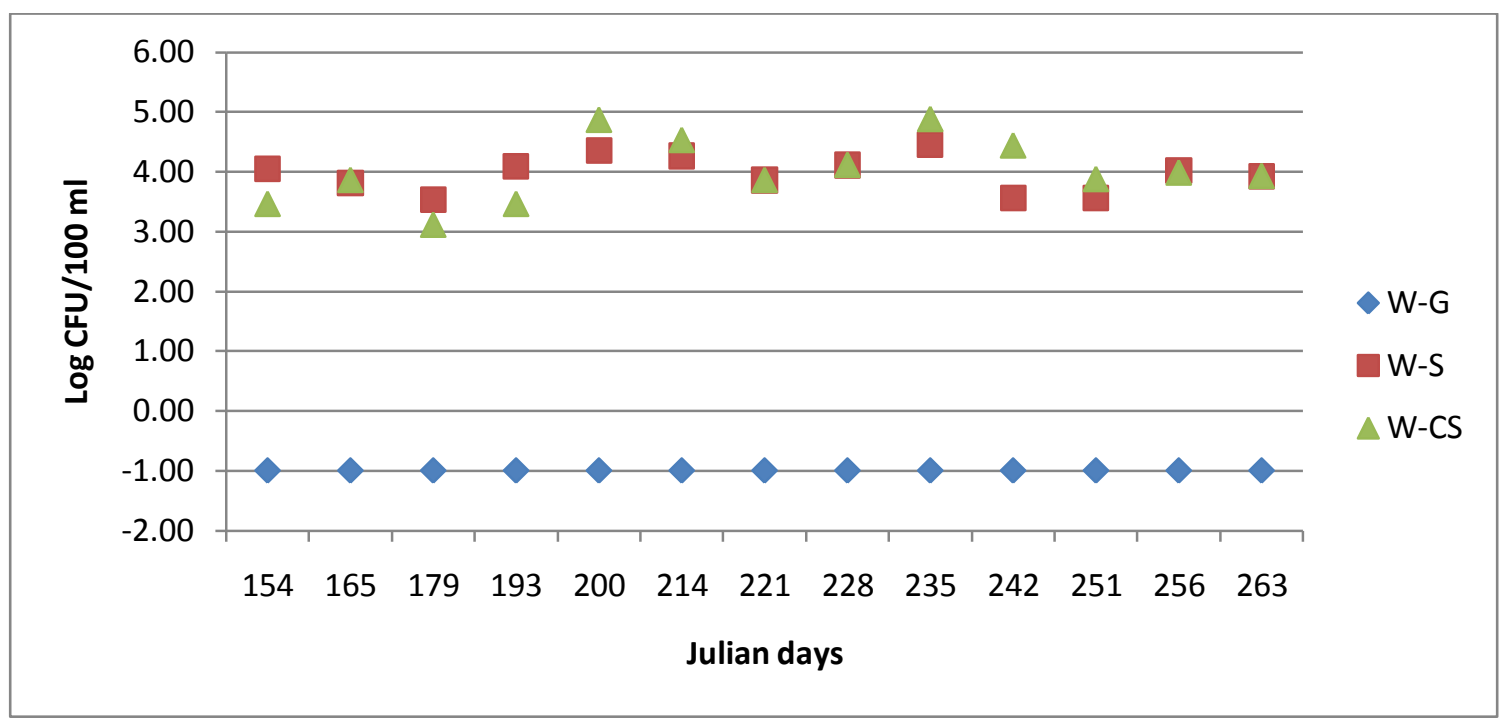

Figure 2-1. Change of Enterobacteriaceae counts over the course of the 2009 sampling season. Organized by water source: groundwater (W-G), surface pond (W-S), and a copper-sulfate treated surface pond (W-CS). Counts are the log-transformed means (per $100 \mathrm{ml}$ ) of three replicates.

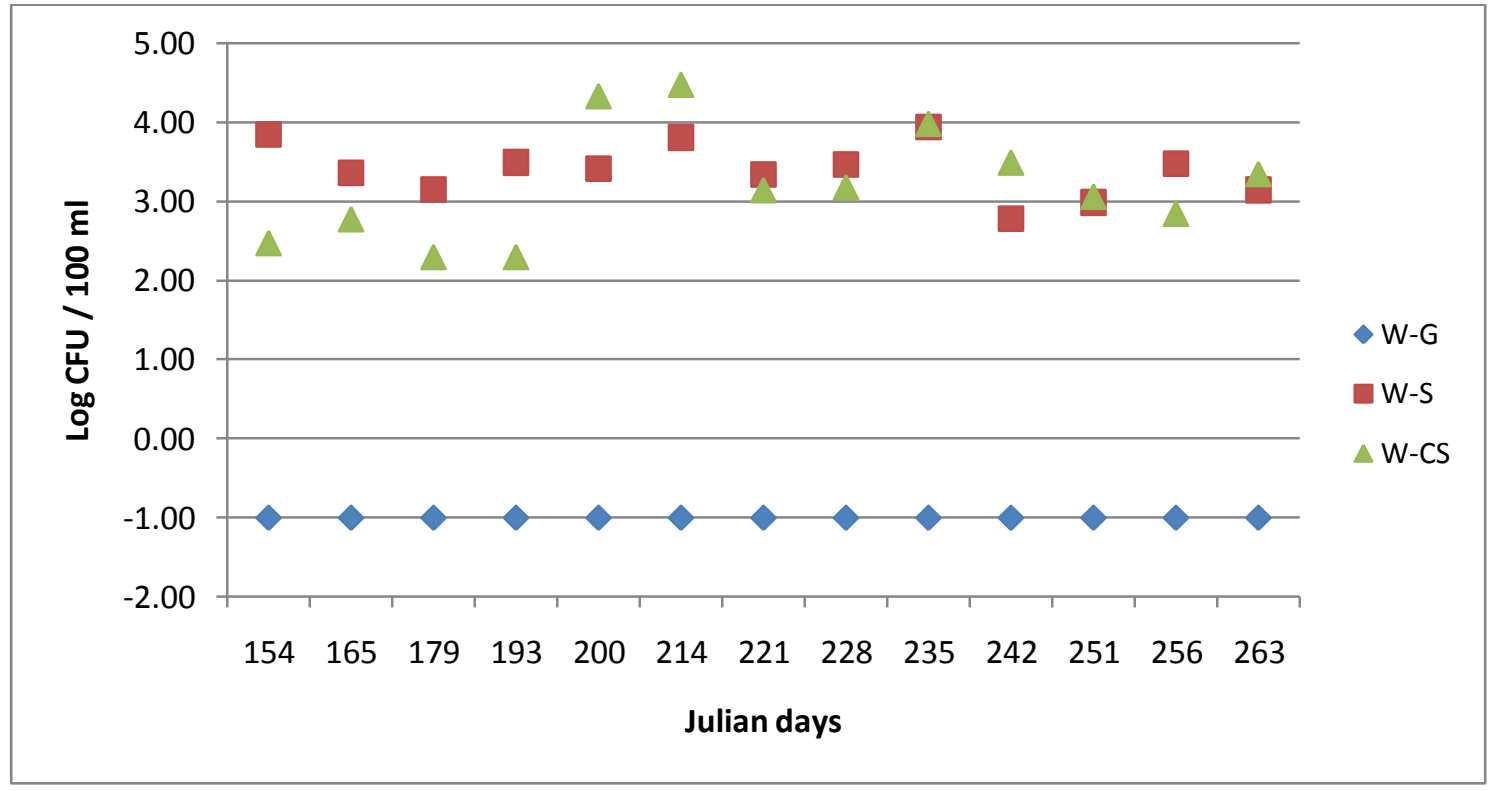

Figure 2-2. Change of total coliform counts over the course of the 2009 sampling season. Organized by water source: W-G, W-S, and W-CS. Counts are the log-transformed means (per $100 \mathrm{ml}$ ) of three replicates. 


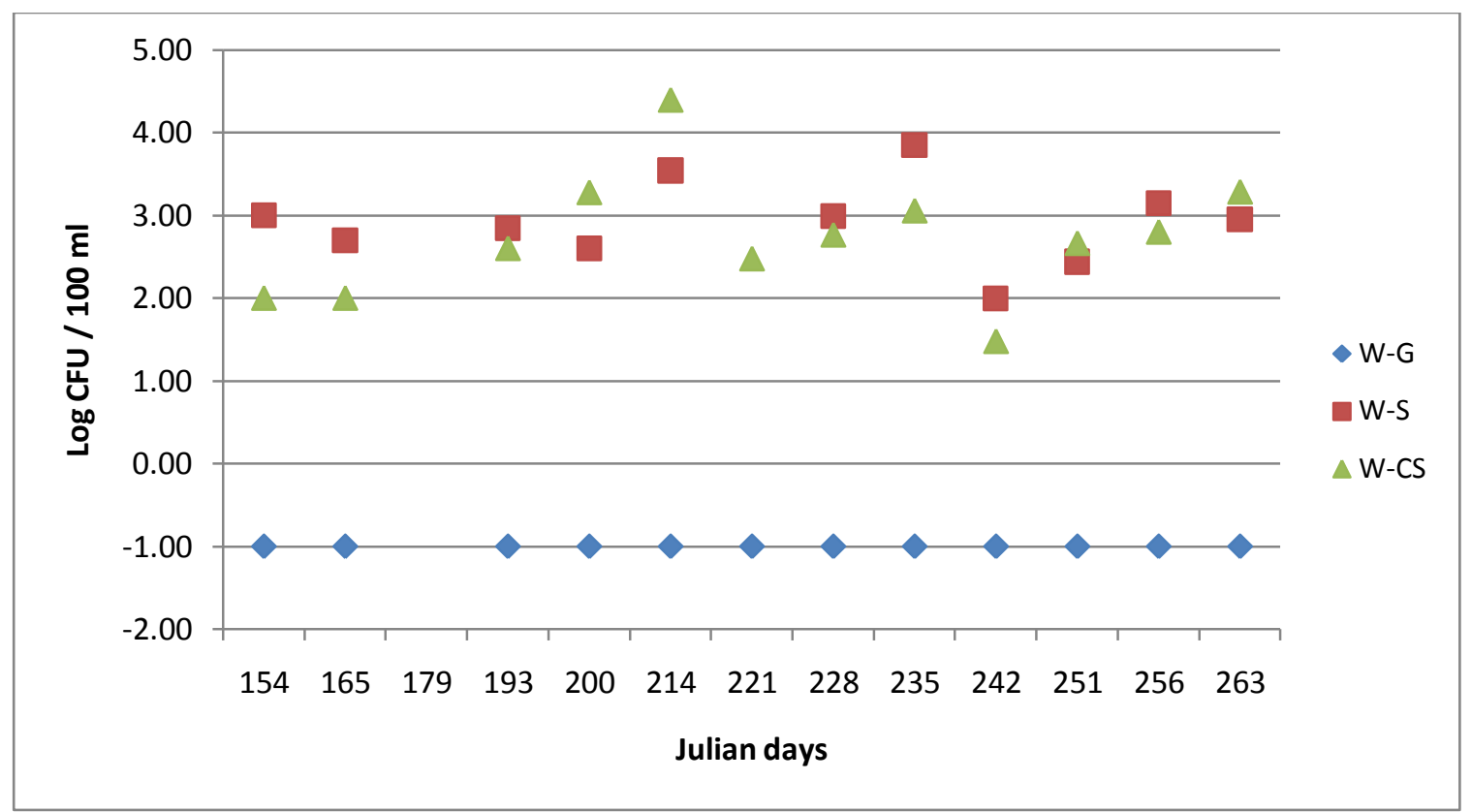

Figure 2-3. Change of fecal coliform counts over the course of the 2009 sampling season. Organized by water source: W-G, W-S, and W-CS. Counts are the log-transformed means (per $100 \mathrm{ml}$ ) of three replicates. 
As mentioned above, W-G samples had counts of $0 \log \mathrm{CFU} / 100 \mathrm{ml}$ in all of the 2010 sampling dates (Figs. 2-4 to 2-7). Counts of Enterobacteriaceae in the W-S fluctuated between 3.04 and $4.93 \log$ CFU/100 $\mathrm{ml}$ and W-CS samples varied between 3.50 and $6.3 \log$ CFU/100 ml in the 2010 sampling season (Fig. 2-4). The total coliform counts in W-S ranged between 2.00 and $4.54 \log$ CFU/100 $\mathrm{ml}$ and W-CS fluctuated between 2.00 and $5.42 \log$ CFU/100 ml (Fig. 25 ). The counts for both fecal coliforms and E. coli fluctuated markedly during the course of this season, but were generally lower than the Enterobacteriaceae and total coliform counts. In the W-S samples, fecal coliforms ranged from -1 to $4.53 \log \mathrm{CFU} / 100 \mathrm{ml}$, and the E. coli counts fluctuated between -1 and $4.1 \log$ CFU/100 ml during 2010 sampling (Figs. 2-6; 2-7). Total coliforms in W-CS ranged between 2.00 and $5.16 \log$ CFU/100 ml, and the E. coli fluctuated between -1 and $2.60 \log$ CFU/100 ml (Figs. 2-6; 2-7). 


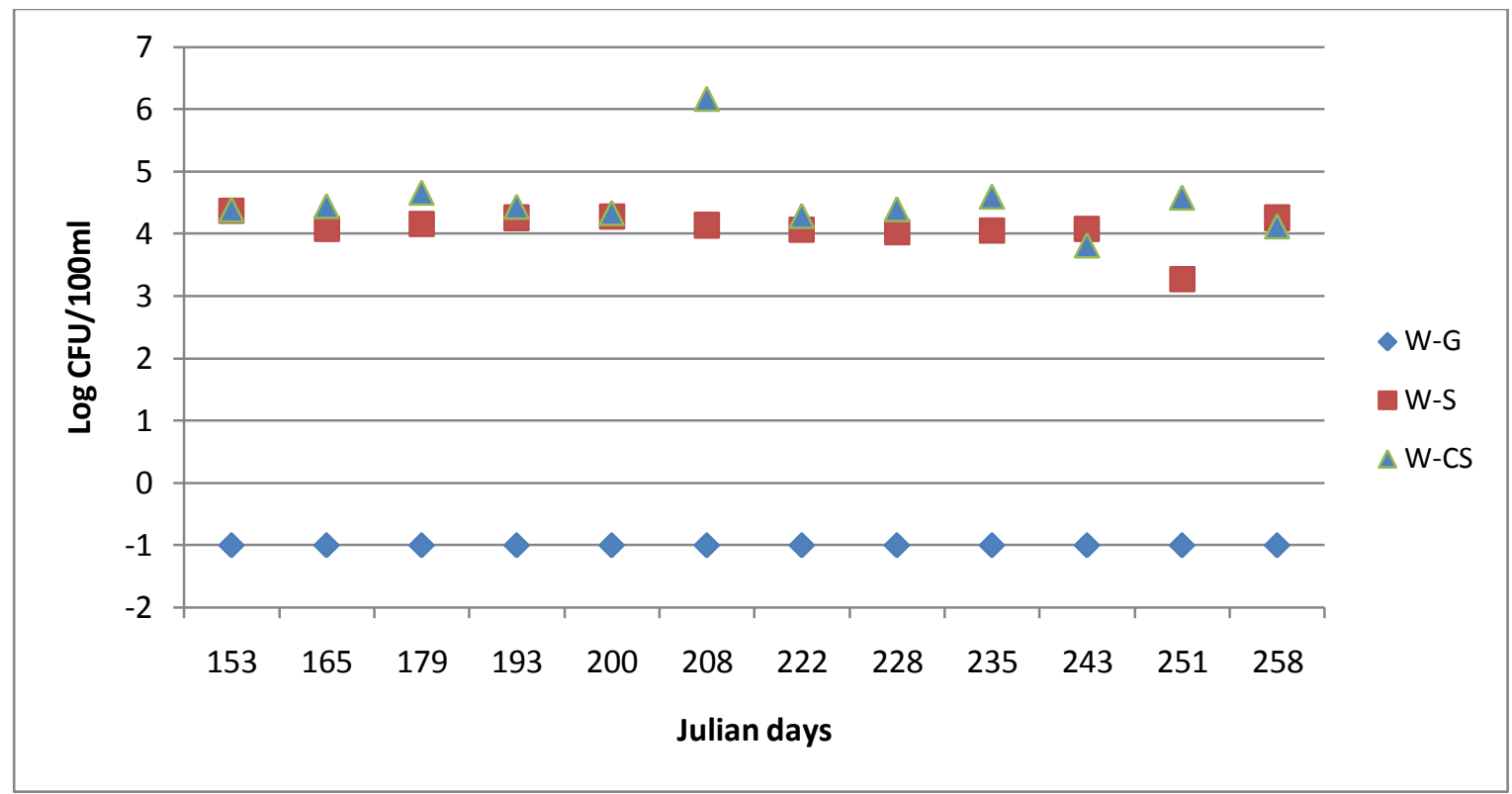

Figure 2-4. Change of Enterobacteriaceae counts over the course of the 2010 sampling season. Organized by water source: W-G, W-S, and W-CS. Counts are the log-transformed means (per $100 \mathrm{ml}$ ) of three replicates.

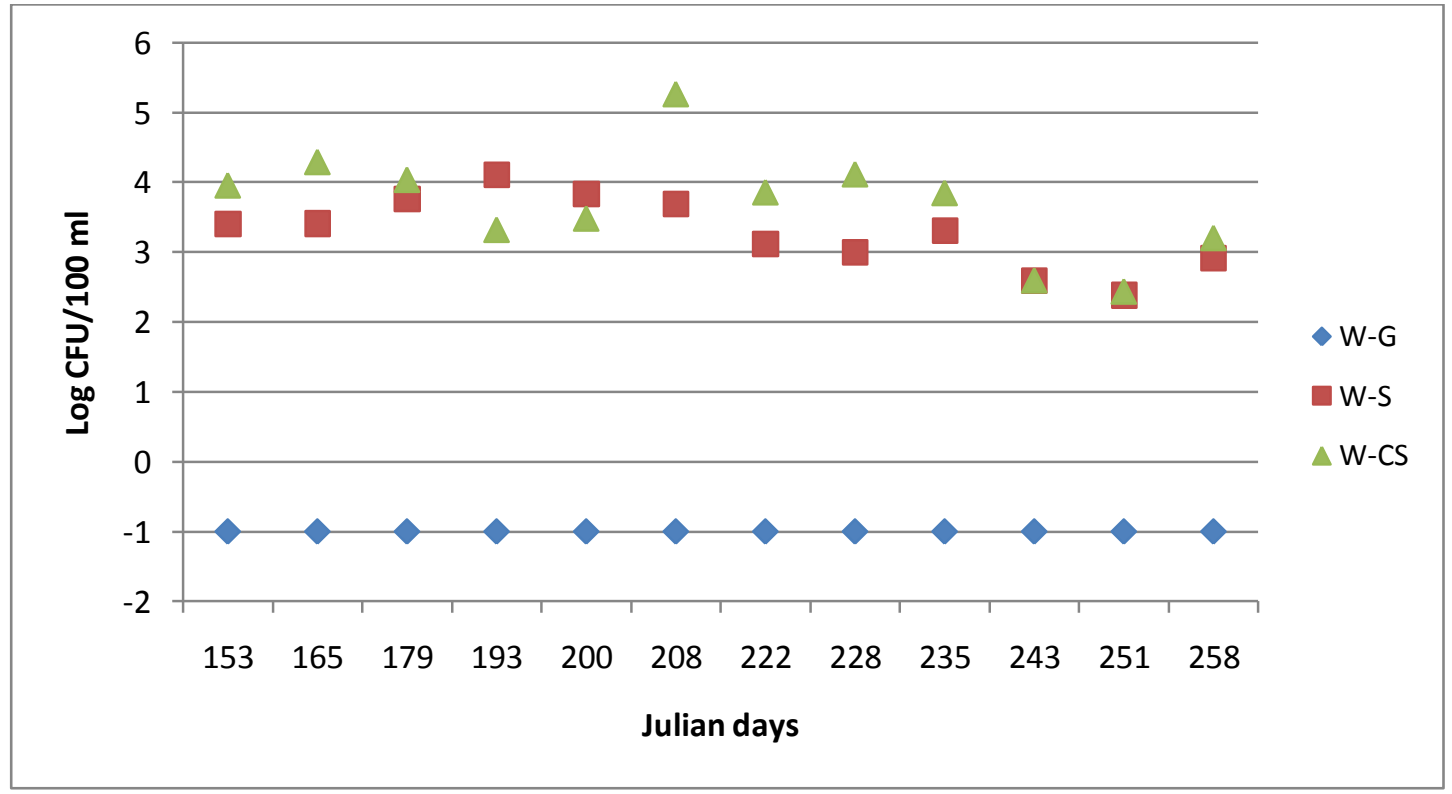

Figure 2-5. Change of total coliform counts over the course of the 2010 sampling season. Organized by water source: W-G, W-S, and W-CS. Counts are the log-transformed means (per $100 \mathrm{ml}$ ) of three replicates. 


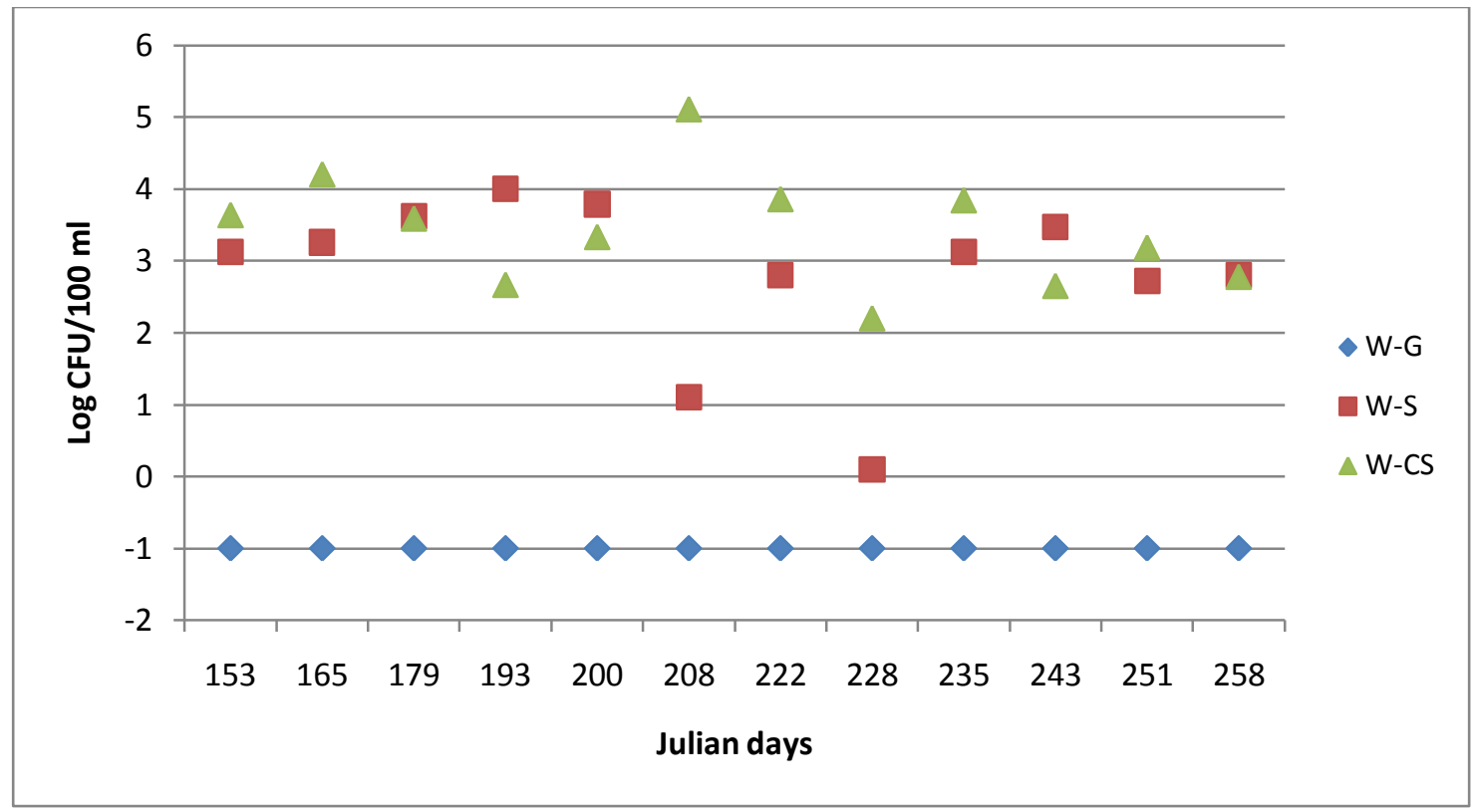

Figure 2-6. Change of fecal coliform counts over the course of the 2010 sampling season. Organized by water source: W-G, W-S, and W-CS. Counts are the log-transformed means (per $100 \mathrm{ml}$ ) of three replicates.

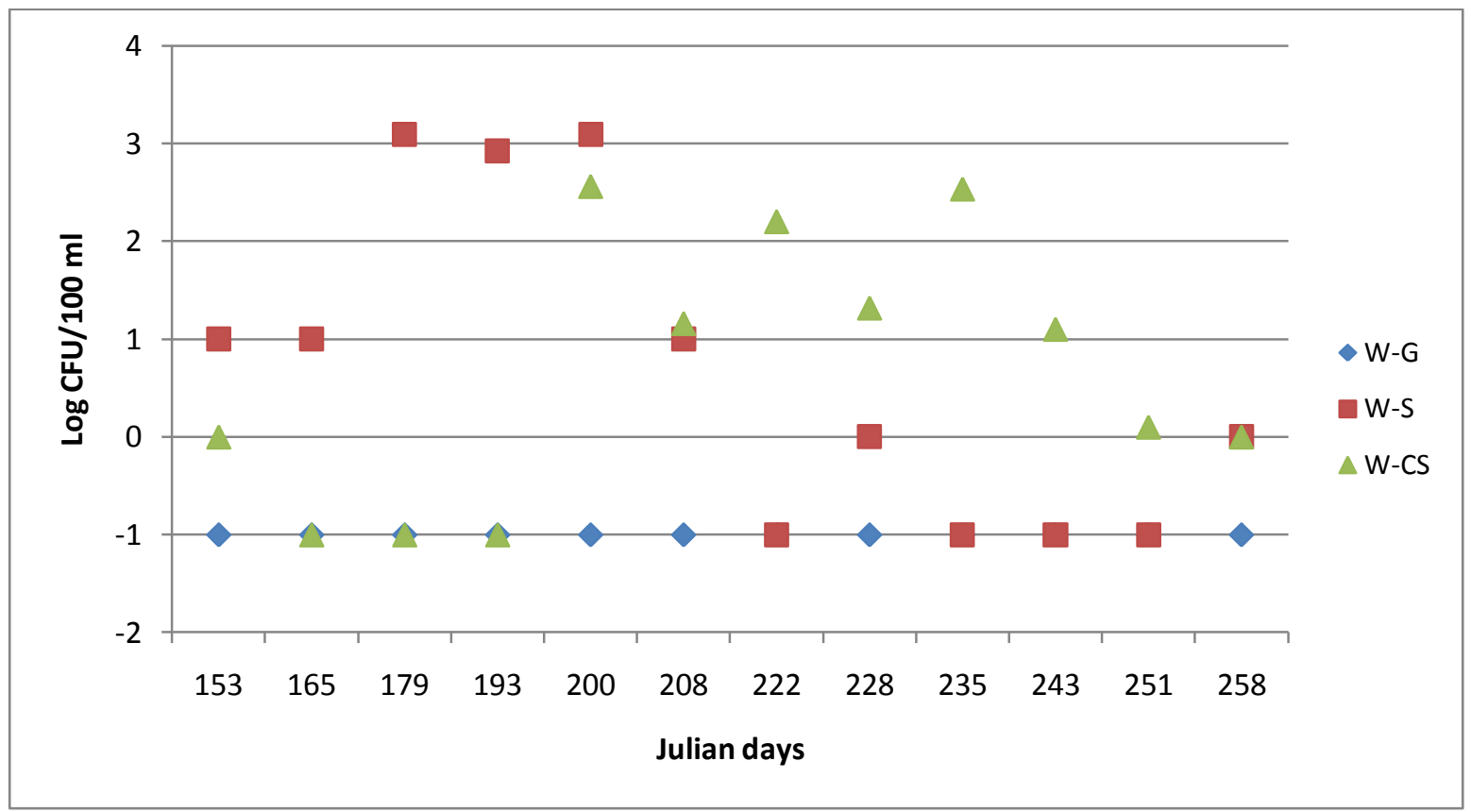

Figure 2-7. Change of E. coli counts over the course of the 2009 sampling season. Organized by water source: W-G, W-S, and W-CS. Counts are the log-transformed means (per $100 \mathrm{ml}$ ) of three replicates. 
Spray catch samples were taken at four sampling dates during the 2010 season. These were compared to the source water samples collected at the same four dates. For the Enterobacteriaceae, total coliforms, and fecal coliforms, there was a significant interaction between water source, date, and sample type $(P<0.0001)$. This indicates that the water sampled from the source and the water used in treatment applications varied significantly for these indicator organisms (Table 2-1). The only significant difference between the spray catch samples and source samples appeared in W-G. For each of the fecal indicator organisms in this water source, measured spray catch levels were higher than the source samples (Table 2-1). The levels of Enterobacteriaceae were up to $4 \log \mathrm{CFU} / 100 \mathrm{ml}$ higher in the spray catches than at the measured water sources. The levels of total coliforms and fecal coliforms in W-G did not show such a great difference (Figs. 2-5; 2-6). The differences between spray source and pond source were not as large in the W-S and W-CS samples and had no significant difference (Table 2-1). Across the three water sources, source versus spray catch had no significant effect on the counts of E. coli (Table 2-1). 


\begin{tabular}{|c|c|c|c|c|c|}
\hline \multirow{2}{*}{ Tomato Treatment } & Sample Type & Enterobacteriacea** & Total Coliforms* & Fecal coliforms* & E. coli \\
\hline \multirow{2}{*}{ W-G } & Source & $-1.00 \mathrm{a}$ & $-1.00 \mathrm{a}$ & $-1.00 \mathrm{a}$ \\
\cline { 2 - 5 } & Spray catch & $3.40 \mathrm{~b}$ & $0.78 \mathrm{~b}$ & $1.37 \mathrm{~b}$ \\
\hline \multirow{2}{*}{ W-S } & Source & $3.88 \mathrm{a}$ & $3.12 \mathrm{a}$ & $2.44 \mathrm{a}$ \\
\cline { 2 - 5 } & Spray catch & $3.81 \mathrm{a}$ & $2.95 \mathrm{a}$ & $2.55 \mathrm{a}$ \\
\hline \multirow{2}{*}{ W-CS } & Source & $4.91 \mathrm{a}$ & $3.85 \mathrm{a}$ & $0.30 \mathrm{a}$ \\
\cline { 2 - 5 } & Spray catch & $5.05 \mathrm{a}$ & $4.40 \mathrm{a}$ & $4.00 \mathrm{a}$ & $1.50 \mathrm{a}$ \\
\hline
\end{tabular}

* Different letters within a column indicate significant differences.

Table 2-1. Level of four indicator organisms in two sample types (source and spray catch) across three water sources. Logtransformed data is reported as $\log \mathrm{CFU} / 100 \mathrm{ml}$, and is the mean of 3 repetitions and 4 sampling dates in 2010 (Tukey means comparison test, $\mathrm{P}<0.05)$. 


\section{Environmental effects}

Air temperature and precipitation at WREC were recorded daily at a permanent weather station. Water temperature and $\mathrm{pH}$ measurements were taken at each sampling date for each water source. Since the W-G samples had no detectable colony counts, only samples from the two surface ponds (W-S and W-CS) were included for environmental analyses. A stepwise regression model was run on the fecal indicator organisms using date, water source, and a number of environmental factors. Regression data are presented in Table 2-2. For the 2009 data, precipitation, water temperature, and Julian day had a significant effect on the levels of Enterobacteriaceae in the pond water, whereas water temperature, $\mathrm{pH}$, and date had a significant effect on the levels of total coliforms in the pond water samples. Fecal coliform variation was explained by the water temperature and maximum air temperature levels of the previous day. Although each of these variables played a significant role in bacterial counts, the regression models explained only $12 \%$ to $32 \%$ of the variation among the measured counts in these waters.

In 2010, source, date, and the maximum air temperature played a significant role in growth of Enterobacteriaceae, and source, water temperature, maximum air temperature, and $\mathrm{pH}$ had a significant effect on the number of total coliforms present in the W-S and W-CS sources. Only $\mathrm{pH}$ and date had a significant effect on fecal coliforms. Water temperature had a very small but statistically-significant effect on $E$. coli counts, with an $\mathrm{R}^{2}$ value of 0.03 (Table 2-2). 


\begin{tabular}{|c|c|c|c|c|c|c|c|c|}
\hline Year & Indicator Organism & Intercept & $\begin{array}{c}\text { Max Air } \\
\text { Temp }\left({ }^{\circ} \mathrm{C}\right)\end{array}$ & $\begin{array}{c}\text { Water } \\
\text { Temp }\left({ }^{\circ} \mathrm{C}\right)\end{array}$ & $\mathrm{pH}$ & Date & $\begin{array}{l}\text { Precip } \\
(\mathrm{mm})\end{array}$ & Model $\mathrm{R}^{2}$ \\
\hline \multirow{3}{*}{2009} & Enterobacteriaceae & $1.335(0.11)$ & $N S$ & $\begin{array}{l}0.067 \\
(0.002)\end{array}$ & $N S$ & $0.004(0.07)$ & $0.006(0.02)$ & 0.33 \\
\hline & Total Coliforms & $1.929(0.08)$ & $N S$ & $\begin{array}{c}0.083 \\
(0.0005)\end{array}$ & $\begin{array}{l}-0.233 \\
(0.003)\end{array}$ & $0.005(0.02)$ & $N S$ & 0.34 \\
\hline & Fecal Coliforms & $\begin{array}{l}2.201 \\
(0.039)\end{array}$ & $-0.97(0.08)$ & $0.127(0.02)$ & $N S$ & $N S$ & $N S$ & 0.12 \\
\hline \multirow{4}{*}{2010} & Enterobacteriaceae & $\begin{array}{c}6.673 \\
(<0.0001)\end{array}$ & $\begin{array}{l}-0.043 \\
(0.06)\end{array}$ & $N S$ & $N S$ & $\begin{array}{l}0.0004 \\
(0.03)\end{array}$ & $N S$ & 0.25 \\
\hline & Total Coliforms & $\begin{array}{c}4.671 \\
(0.0003)\end{array}$ & $\begin{array}{l}-0.100 \\
(0.002)\end{array}$ & $\begin{array}{c}0.167 \\
(<0.0001)\end{array}$ & $\begin{array}{l}-0.277 \\
(0.015)\end{array}$ & $N S$ & $N S$ & 0.36 \\
\hline & Fecal Coliforms & $1.516(0.25)$ & $N S$ & $N S$ & $\begin{array}{l}0.409 \\
(0.002)\end{array}$ & $\begin{array}{l}-0.008 \\
(0.02)\end{array}$ & $N S$ & 0.2 \\
\hline & E. coli & $-2.300(0.26)$ & $N S$ & $0.104(0.15)$ & $N S$ & $N S$ & $N S$ & 0.03 \\
\hline
\end{tabular}

Note: Numbers in parenthesis are p-values from an Analysis of Variance.

Variables with $P>0.15$ were marked as Non-significant (NS).

Table 2-2. Change in Enterobacteriaceae, total coliforms, fecal coliforms, and E. coli as described by several environmental variables over the 2009 and 2010 sampling seasons. Values are the coefficients of a regression equation (following a stepwise regression). 
Effect of water quality on the microbial load of fecal indicator organisms on grape tomato fruit surfaces

The enumeration of bacteria from the grape tomato phyllosphere did not clearly follow the indicator organisms in each of the water sources used for pesticide treatment. Phyllosphere bacteria counts from the 2009 sampling season showed no significant differences over date, however treatment had a significant effect $(\mathrm{P}<0.05)$. In the 2010 sample season date had a significant effect (Enterobacteriaceae and fecal coliforms).The water source significantly affected the Enterobacteriaceae counts. In 2009, the tomatoes treated with groundwater (Phy-G) had a significantly higher number of total coliforms (3.41 log CFU/100 ml) than surface water treated tomatoes (Phy-S)(1.29 log CFU/100 ml). Tomatoes treated with copper sulfate water (Phy-CS) had a mean count of $1.89 \log$ CFU/100 ml total coliforms. Phy-S tomatoes had significantly higher fecal coliform counts (4.02 log CFU/100 ml) than both the Phy-G (2.67 log CFU/100 ml) and Phy-CS (2.46 log CFU/100 ml). Whole seasonal averages for all indicator organisms studied are displayed in Table 2-3. Tomatoes had no significant differences in counts of Enterobacteriaceae between the three treatments in 2009. In 2010, the Phy-G samples had significantly lower counts of Enterobacteriaceae than the Phy-S and Phy-CS counts. The remaining three indicator organisms showed no significant differences in bacterial counts in response to treatment (Table 2-3). 


\begin{tabular}{|c|c|c|c|c|c|}
\hline Year & $\begin{array}{c}\text { Tomato } \\
\text { Treatment }\end{array}$ & Enterobacteriaceae & $\begin{array}{c}\text { Total } \\
\text { Coliforms }\end{array}$ & $\begin{array}{c}\text { Fecal } \\
\text { Coliforms }\end{array}$ & E. coli \\
\hline \multirow[t]{3}{*}{2009} & Phy-G & $4.97 \mathrm{a}$ & $3.40 \mathrm{a}$ & $2.66 \mathrm{a}$ & --- \\
\hline & Phy-CS & $4.56 \mathrm{a}$ & $1.89 \mathrm{ab}$ & $2.45 \mathrm{a}$ & --- \\
\hline & Phy-S & $4.83 \mathrm{a}$ & $1.28 \mathrm{~b}$ & $4.01 \mathrm{~b}$ & --- \\
\hline \multirow[t]{3}{*}{2010} & Phy-G & $4.32 \mathrm{a}$ & $2.40 \mathrm{a}$ & $2.10 \mathrm{a}$ & $-1.00 \mathrm{a}$ \\
\hline & Phy-CS & $5.28 b$ & $1.89 \mathrm{a}$ & $2.44 \mathrm{a}$ & $-0.89 a$ \\
\hline & Phy-S & $4.76 \mathrm{ab}$ & $2.27 \mathrm{a}$ & $2.52 \mathrm{a}$ & $-1.00 \mathrm{a}$ \\
\hline
\end{tabular}

Means followed by different letters are significantly different $(P<0.05)$ based upon Tukey analysis.

Table 2-3. Summary of 2009 and 2010 fecal indicator organism counts on grape tomato fruit surface, organized by water source treatments. Means are presented as Log CFU / $100 \mathrm{ml}$ water. 


\section{Salmonella}

Salmonella tests using the RapidChek Salmonella TestKit were completed on water samples on the dates of June 29, August 17, and August 31, 2009, and July 19 and August 23, 2010. The surface of grape tomato fruits were tested on the dates of August 17 and August 31, 2009, and August 23, 2010. All samples, including both water and phyllosphere samples, were found to be negative in all instances.

\section{Discussion}

Bacterial counts from W-G were significantly lower than those from W-CS and W-S in 2009 and 2010. One exception was the E. coli counts from 2010 where limited colonies were found in the pond samples. This was expected as groundwater sources often have a lower risk of fecal contamination in that they are not open to surface contamination and the soil's natural ability to filter out pathogens (Fan et al., 2009; Sylvia et al., 2005). Surface water sources such as W-S and W-CS are uncovered and can be inhabited by wildlife and are therefore at higher risk of contamination. These factors might explain the higher levels of Enterobacteriaceae, total coliforms, fecal coliforms, and E. coli observed in the W-S and W-CS samples.

Enterobacteriaceae and total coliforms were variable throughout the season, reaching maximum values of up to $6 \log \mathrm{CFU} / 100 \mathrm{ml}$ in the $\mathrm{W}-\mathrm{S}$ and $\mathrm{W}-\mathrm{CS}$ samples whereas the fecal coliforms varied up to $5 \log \mathrm{CFU} / 100 \mathrm{ml}$, showing more variability in the 2010 sampling season. These fluctuations were dependent upon sampling date and several environmental factors: maximum air temperature from the previous day, total precipitation in the 3 days prior to sampling, water 
temperature, and $\mathrm{pH}$ of the water. The environmental variables that caused a significant change in bacterial counts differed in the two years of this study and also indicator organism. Water temperature had a significant effect, on total coliform counts but not Enterobacteriaceae and fecal coliform counts. These environmental variables measured only explained up to $34 \%$ of the variability in bacterial counts in the two surface water sources used in this study. Therefore, it is possible that additional environmental variables should be taken into consideration to predict bacterial counts. Certain environmental variables such as $\mathrm{pH}$ and water temperature have also diurnal patterns which fluctuate in the course of one day (Hong et al., 2009). Such patterns were not measured in this study, and may explain the lack of correlation between our colony counts and measured environmental variables.

Additional studies have shown that bacterial inactivation is determined by several environmental factors, including light intensity, temperature, $\mathrm{pH}$, and turbidity (SchultzFademrecht et al., 2008). A study of E. coli survival in a tropical estuary showed that sunlight was the most important inactivation factor (Chandran et al., 2005). Ultraviolet radiation (a measure of light intensity) damages microbial DNA, thereby causing inactivation. The same study found that predatory organisms such as protozoans and bacteriophages exerted considerable pressure on the E. coli populations, although the dissolved organic and inorganic substances in the environment did not affect E. coli inactivation (Chandran et al., 2005).

Agencies such as the World Health Organization and United Fresh Produce Association have adopted microbial standards for the use of agricultural water to prevent the contamination of tomatoes and foodborne illness outbreaks resulting from their consumption (Blumenthal et al., 2000b; Gombas, 2008). These guidelines are based upon the EPA standards for freshwater recreational water (for non-foliar application of agricultural water, such as trickle irrigation), 
allowing for a geometric mean of $126 \mathrm{CFU}$ E. coli per $100 \mathrm{ml}$ water (EPA, 2008; Gombas, 2008). This is equivalent to $2.1 \log$ CFU per $100 \mathrm{ml}$. The levels of $E$. coli in W-S and W-CS exceeded this standard on several dates throughout 2010. On Julian days 179 and 193 (June 28 and July 12), W-S exceeded the standard by up to $1 \mathrm{log}$, and on day $200 \mathrm{~W}-\mathrm{S}$ and W-CS both exceeded the standard. In 2010 W-CS contained higher amounts of E. coli on two later dates, at 222 and 235. These results demonstrate the variability in microbial levels over the course of a sampling season and the need for farmers to submit water samples for microbial analysis on multiple dates throughout the season. The US FDA has no mandatory requirements for frequency of sampling to monitor the microbial suitability of agriculture contact water.

The United Fresh Produce Association (UFPA) also published guidelines on the recommended level of $E$. coli allowed for water used in foliar applications of pesticides and irrigation. Since the water may directly contact the tomato fruit these standards are based upon EPA standards for potable water: 0 CFU (undetectable levels) of E. coli per $100 \mathrm{ml}$. Based on this standard in the 2010 season, only the groundwater samples in this study would be suitable for surface application to the tomato plants. W-CS would have been permissible for use in irrigation applications during the period comprising the three first sampling dates in the season (Julian dates 165, 179, 193) and W-S on several dates toward the end of the season (Julian dates 235, 243, 251). Again, the variability in E. coli counts indicates a need for frequent water sampling throughout the season.

Water sampling type (collecting water samples from the source as opposed to the spray catches) only had a significant effect on the W-G samples, with higher counts of Enterobacteriaceae, total coliforms, and fecal coliforms recorded in the spray catch samples. Separate spray manifolds were used for each treatment, however it is possible that contamination 
occurred between sampling dates. A floating white precipitate was observed in some of the groundwater spray catch samples and although each spray manifold was rinsed and sample water was flushed through the manifolds before each sampling, it is possible that the white precipitate is spray residue from the previous sampling. Suspended solids within a water sample increase the amount of surface area that bacteria can attach to and colonize, thus bacterial colonization is often associated with a higher degree of turbidity and suspended solids (Fan et al., 2009; Obi et al., 2008). Studies show that turbidity is correlated with total coliforms, because the increased surface area allows for attachment and the formation of biofilms that protect from antimicrobials and environmental variables (Obi et al., 2008; Or et al., 2007). Despite the efforts to prevent bacterial contamination, the spray catches for the W-G source still showed elevated counts. This shows that disinfection and proper storage of pesticides and equipment can also play a significant role in preventing food-borne illnesses.

Bacterial levels in the water source did not correspond with the bacterial levels on the grape tomato phyllosphere. In most instances, the significantly higher mean bacterial counts in the two pond sources were not reflected in the phyllosphere. In 2010, the only significant difference in counts occurred in Enterobacteriaceae: Phy-G samples had a lower count than the Phy-CS samples by approximately 1 log CFU per $100 \mathrm{ml}$. In 2009, Phy-G had a higher count of total coliforms than Phy-S, however Phy-S had a significantly higher level of fecal coliforms than Phy-G and Phy-CS. These results indicate that there are other factors affecting bacterial colonization of the tomato phyllosphere, so that the bacterial load of applied pesticide treatments may have had less effect than predicted. A five-year study of reclaimed wastewater usage in agriculture reported similar results when applied to several horticultural crops (Burau et al., 
1987). Although the reclaimed wastewater had significantly higher total coliforms and fecal coliforms, the differences were not reflected in the soil and plant tissue samples.

Other studies have addressed the complex ecological and physical interactions between phyllosphere-associated bacteria and their host plants, indicating that several factors influence the survival of epiphytic bacteria (Enya et al., 2007b). The tomato phyllosphere environment includes environmental stresses such as UV radiation, high winds, heat, lack of moisture, as well as an acidic $\mathrm{pH}$ and the presence of the antimicrobials glutamic acid and tomatine (Baker et al., 2010; Friedman, 2002; Sajur et al., 2007). These antimicrobials select for the growth of acidtolerant microbes such as Pseudomonas syringae pv.Tomato, and Lactobacillus spp. (Sajur et al., 2007). The smooth texture of tomato skin may also prevent attachment and enhance bacterial sloughing from the fruit surface (Guan et al., 2004). Competition and cooperative relationships among colonized bacteria have a role in the colonization of new bacteria (Enya et al., 2007b), such as those contained in the contact water used to apply pesticides. The combination of environmental factors and stresses from the tomato phyllosphere may have prevented bacteria in the pesticide water from colonizing the tomato fruit surfaces in a measurable fashion.

The pesticides used may also play a role in bacteria's persistence on tomato fruit. Studies showed that Salmonella serovars and E. coli 0157:H7 can survive and amplify within water containing chlorothalonil (Bravo), a popular fungicide and one used in the tomato treatments (Guan et al., 2004). When a cocktail of Salmonella and E. coli were applied to tomato plants with this pesticide mixture, the tomato fruit contained $2 \log \mathrm{CFU} / \mathrm{g}$ less bacteria than the tomato leaf surfaces. After 45 hours, bacterial levels were greatly reduced on the tomato fruit, presumably due to the smooth surface of the tomato skin (Guan et al., 2004). 
The fecal indicator organisms used in this study were used for their compatibility with current industry and water standards. However, three genera of bacteria (Klebsiella, Enterobacter, and Citrobacter) have been shown to reproduce within the environment and in water systems without requiring a fecal source, which is significant because these genera classify within the fecal indicator organisms Enterobacteriaceae, total coliforms and fecal coliforms (Fan et al., 2009; Tallon et al., 2005). Thus, these indicator organisms cannot serve as completely reliable measures of fecal contamination. In order to obtain a confident measure of microbial quality, it is advisable to use multiple indicator organisms at a time (Obi et al., 2008). Of the fecal indicator organisms used, E. coli is considered the most reliable because it is the only coliform measurement specific to fecal contamination. Unlike other members measured by fecal coliforms tests $E$. coli is not considered to be an environmental organism (Tallon et al., 2005).

Our results demonstrate that the relationship between the microbial quality of agricultural contact water and the surface of grape tomatoes is not as straightforward as previously thought. Despite the significant effect that water source and date had on the counts of Enterobacteriaceae, total coliforms, fecal coliforms, and $E$. coli from the water samples, these differences did not correspond to the water eluted from the grape tomato fruits. Only certain indicator organisms showed a significant difference among treatments, and those results differed between the two sampling seasons. These results justify the need for frequent water testing when monitoring microbial water quality, and suggest that monitoring other sources of contamination may be as important in preventing foodborne illnesses on tomatoes as monitoring just water source. 


\section{Chapter 3 : Effects of Tomato Maturity, Water Temperature and Water pH on Bacterial Counts of Indicator Organisms}

The research presented in Chapter 2 represents two seasons of work testing the hypothesis that changes in agricultural contact water will affect the phyllosphere of 'Juliet' grape tomatoes. Like any research study, additional questions arose while the work was being conducted. Questions about the role of tomato fruit maturity on the phyllosphere were prompted by an initial observation that the first harvest date in 2009 had significantly lower bacterial counts than any later sampling dates. That observation spawned a preliminary maturity trial in 2010. As mentioned in Chapter 2, weather fluctuations appeared to have an impact on bacterial loads in the water sources used for this study. Chapter 3 presents the results and discussion of these additional studies of maturity and environmental variables.

\section{Maturity data.}

The effect of fruit maturity was tested at two sampling dates in 2010 (July 28 and August 16). Grape tomato fruit samples were collected and processed according to the methodology in chapter 2, with 5 replications from three treatments (15 samples total) for both ripe (red) and unripe (green) tomato samples. Pesticide application treatments had no significant effect, so treatments were pooled and only ripeness and date were compared. Ripeness and date both had significant effects on Enterobacteriaceae: at Julian day 208 unripe and ripe tomatoes had similar counts (3.89 and $3.62 \log$ CFU/ $100 \mathrm{ml}$ ), and at Julian day 228 those counts diverged to 2.82 and $5.14 \log$ CFU/100 ml (Table 3-1). Total coliforms followed a similar trend: at 208 the ripe and unripe tomatoes had similar bacterial levels, and at Julian day 228 the ripe tomatoes had higher 
counts than green tomatoes. Fecal coliform counts were also significantly affected by both date and maturity. The unripe samples had a mean count of $2.44 \log$ CFU fecal coliforms per $100 \mathrm{ml}$ on day 208, which decreased to $0.67 \log \mathrm{CFU} / 100 \mathrm{ml}$ on 228. The ripe samples had the opposite occurrence: counts increased over date from 0.63 to $2.46 \mathrm{log}$ CFU/ $100 \mathrm{ml}$. The levels of $E$. coli were close to undetectable in all of the samples (Table 3-1).

Research has been done on the various antimicrobials that tomatoes produce and how levels of such chemicals vary with fruit ripeness. An example of this is tomatine, a tomato glycoalkoloid that disrupts bacterial membranes (Friedman, 2002). However, not much is known about how maturity affects the deactivation of fecal indicator organisms. The above results, especially the counts from Enterobacteriaceae and total coliforms, suggest that maturity may have an impact on the number of indicator organisms on the surface of tomato fruit. As the tomato ripens, the level of tomatine present in the fruit decreases from $500 \mathrm{mg} / \mathrm{kg}$ of fruit to 5 mg/ kg (Enya et al., 2007b; Friedman, 2002). It is possible that this reduction decreases the efficacy of the antimicrobial and allows for bacterial growth. There may be additional characteristics of unripe grape tomatoes that inhibit bacterial attachment, such as the velvety surface of green tomatoes or the levels of various plant metabolites that develop as tomatoes ripen.

Determining the effect of fruit maturity on the level of fecal indicator organisms on the tomato fruit surface is a subject that needs development beyond the preliminary results presented here. Such information may be valuable in determining the food safety risk of tomatoes harvested ripe compared to those harvested green and gassed with ethylene to ripen. Other than conducting preliminary sampling on two dates in 2010, testing the effect of tomato maturity was out of the scope of this project. 


\begin{tabular}{|c|c|c|c|c|c|c|c|c|}
\hline \multirow{2}{*}{$\begin{array}{c}\text { Julian } \\
\text { Day }\end{array}$} & \multicolumn{2}{|c|}{ Enterobacteriaceae* } & \multicolumn{2}{|c|}{ Total Coliforms* } & \multicolumn{2}{|c|}{ Fecal coliforms* } & \multicolumn{2}{|c|}{ E. coli* } \\
\hline & Unripe & Ripe & Unripe & Ripe & Unripe & Ripe & Unripe & Ripe \\
\hline 208 & 3.89 & 3.62 & 0.87 & 0.99 & 2.44 & 0.63 & -1.00 & -1.00 \\
\hline 228 & 2.82 & 5.14 & 1.24 & 2.14 & 0.67 & 2.46 & -0.73 & -1.00 \\
\hline
\end{tabular}

Table 3-1. Preliminary data comparing levels of fecal indicator organisms (Enterobacteriaceae, total coliforms, fecal coliforms, and E. coli) on different maturity levels of grape tomato fruit during two dates in 2010. Means are presented as Log CFU/ $100 \mathrm{ml}$. 


\section{Environmental data.}

In order to determine the effect of water temperature on bacterial counts in $\mathrm{W}-\mathrm{S}$ and $\mathrm{W}$ $\mathrm{CS}$, a regression was run on the levels of Enterobacteriaceae, total coliforms, fecal coliforms, and E. coli over water temperature. These results of the regression analyses are shown in Figs. 31 to 3-4. In 2009, in W-S, significant $\mathrm{R}^{2}$ values were found for Enterobacteriaceae and total coliforms, respectively explaining $18 \%$ and $25 \%$ of variation in the bacterial counts $(\mathrm{P}=0.03$ and $\mathrm{P}=0.01$ ). Water temperature did not explain a significant amount of variation in fecal coliforms in surface water, nor in any indicator organisms in W-CS. In 2010, water temperature explained $43 \%$ of variation in total coliforms in $\mathrm{W}-\mathrm{S}(\mathrm{P}<0.0001)$, although water temperature was not significant for any other fecal indicator organisms in W-S or W-CS. To determine the effect of $\mathrm{pH}$ on bacterial counts in the surface water sources, a regression was run on the levels of Enterobacteriaceae, total coliforms, and fecal coliforms over $\mathrm{pH}$. An example of the results can be seen in Figure 3-5. In 2009, pH caused 38\% and 37\% of variation in Enterobacteriaceae and total coliforms in $\mathrm{W}-\mathrm{CS}(\mathrm{P}=0.0008$ and $\mathrm{P}=0.0013)$. $\mathrm{pH}$ had no significant effect on fecal coliforms in W-CS and in any indicator organisms in W-S. In 2010, pH had no significant effect on fecal indicator organisms in W-S and W-CS. 


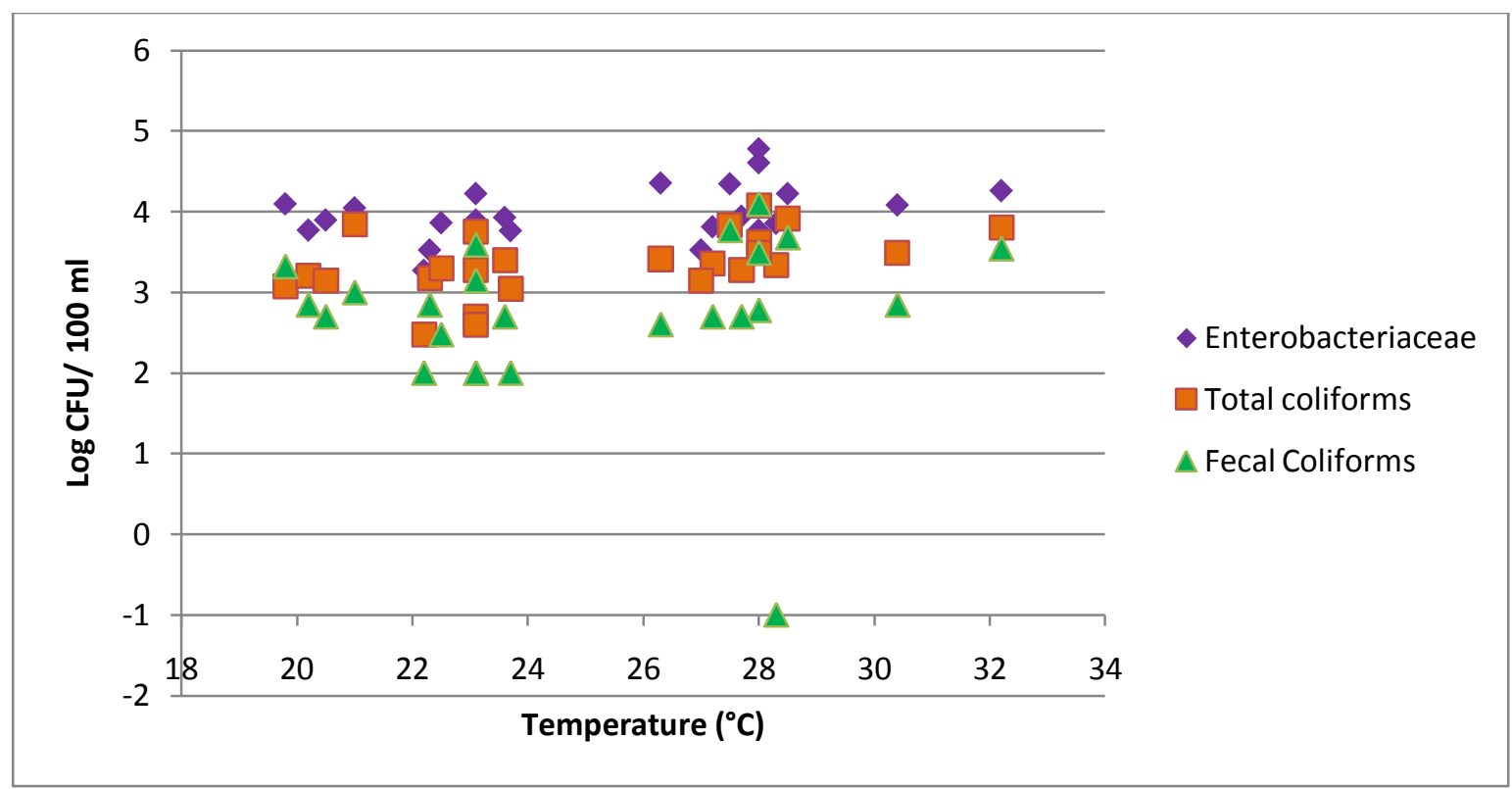

Figure 3-1. Effect of water temperature in W-S on the growth of three fecal indicator organisms, (Enterobacteriaceae, total coliforms, and fecal coliforms) during the 2009 sampling season.

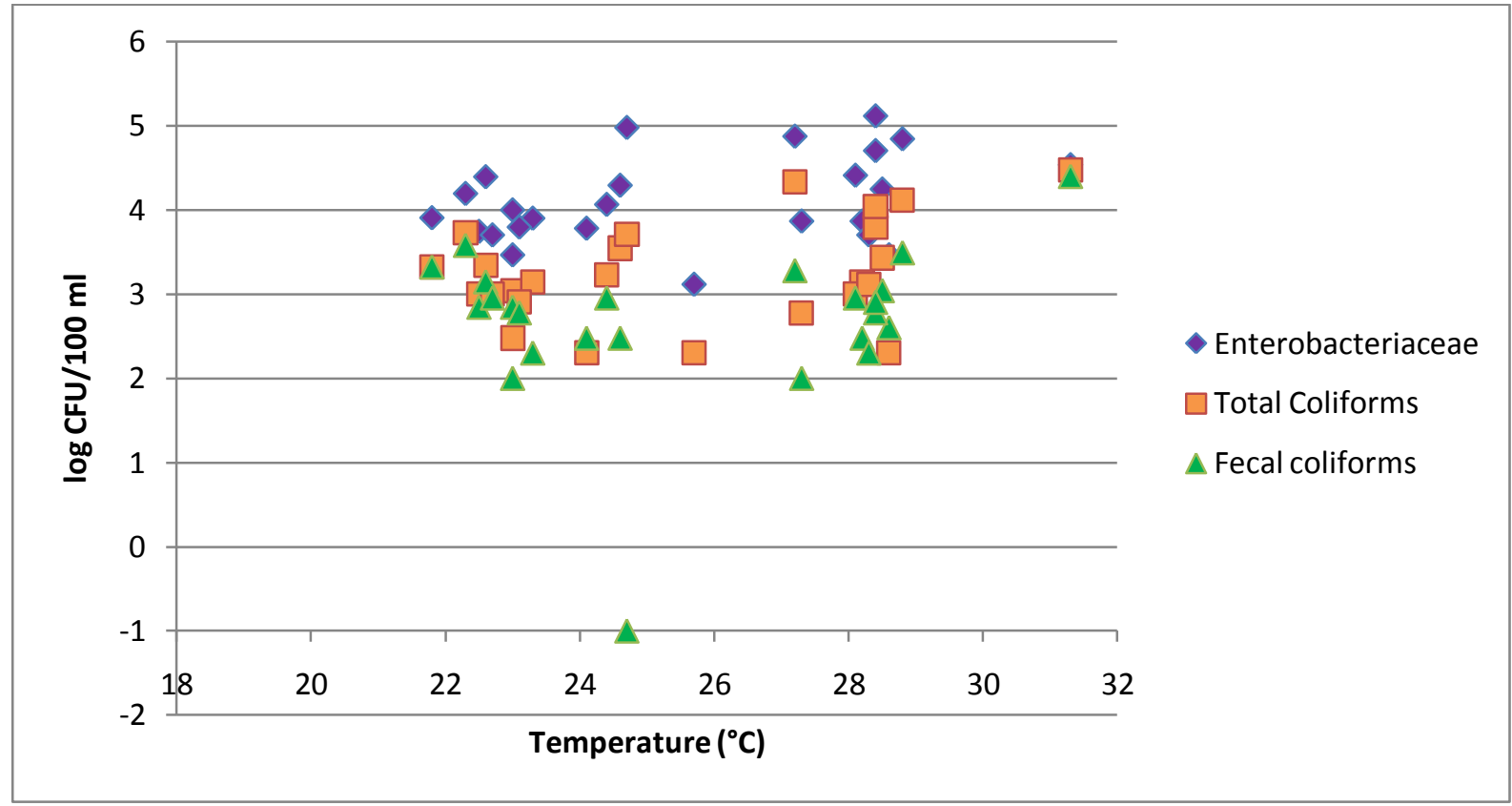

Figure 3-2. The effect of water temperature in W-CS on the growth of fecal indicator organisms (Enterobacteriaceae, total coliforms, and fecal coliforms) during the 2009 sampling season. 


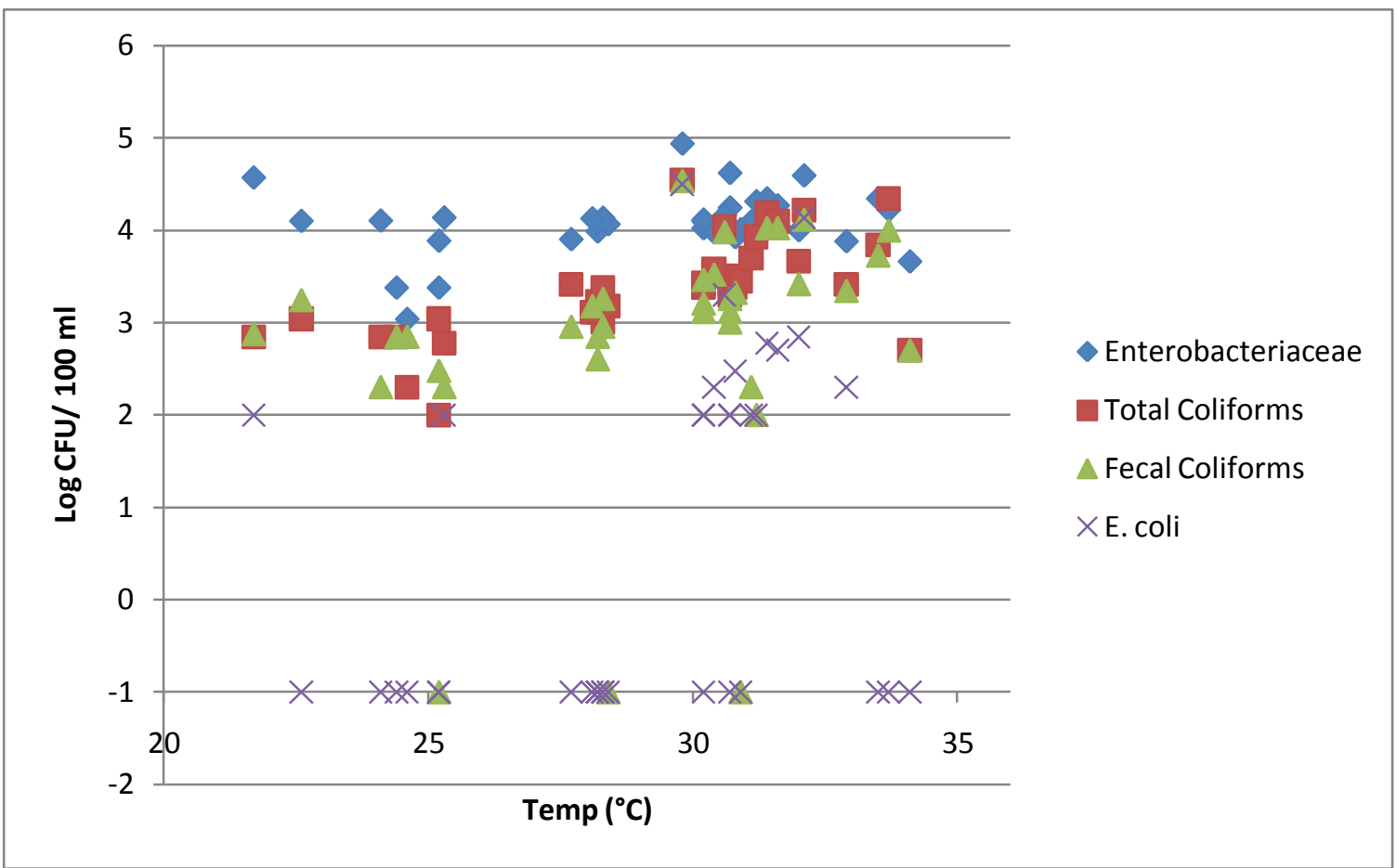

Figure 3-3. The effect of water temperature in W-S on the growth of fecal indicator organisms (Enterobacteriaceae, total coliforms, fecal coliforms, and E. coli) during the 2010 sampling season.

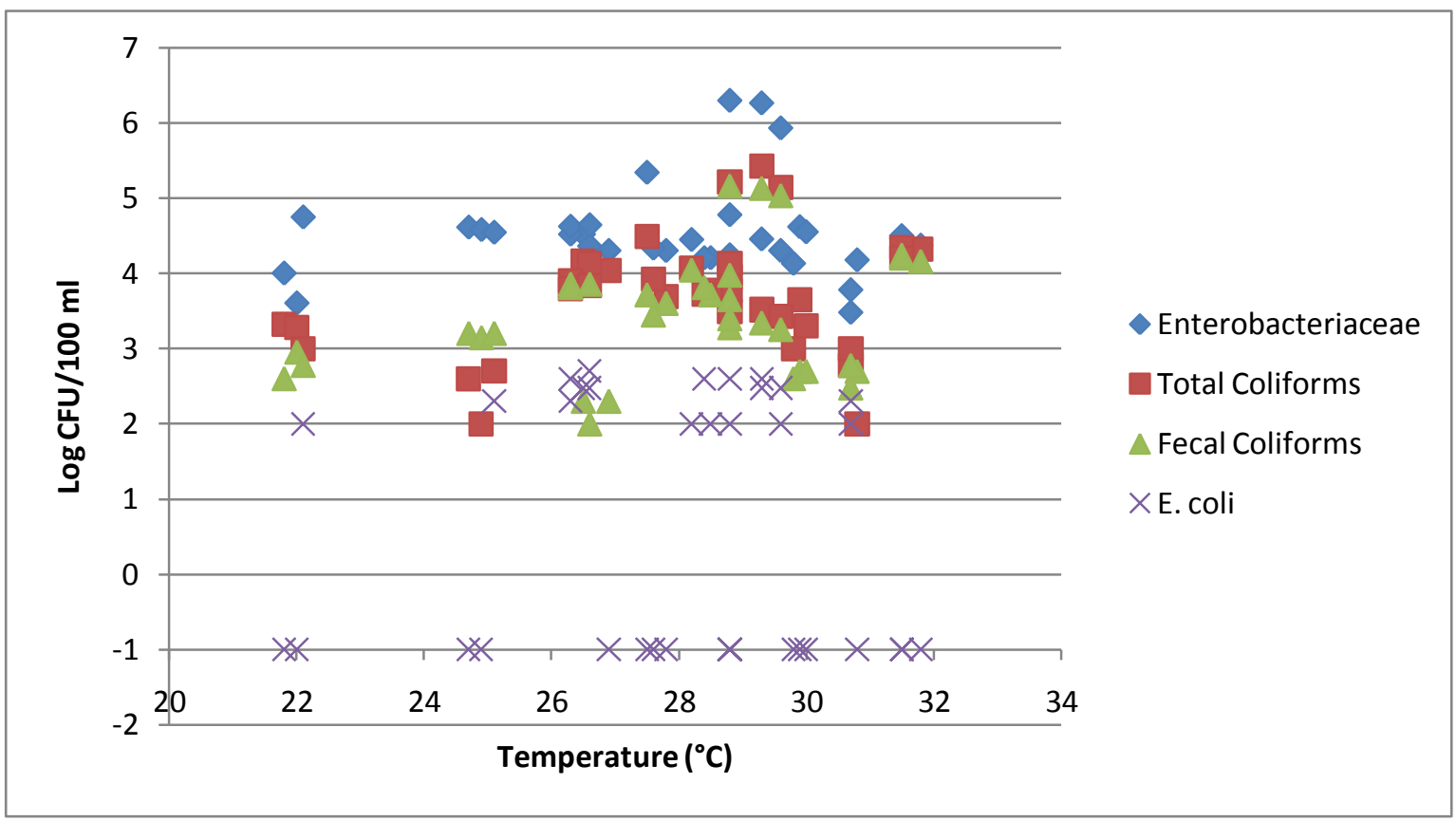

Figure 3-4. The effect of water temperature in W-CS on the growth of fecal indicator organisms (Enterobacteriaceae, total coliforms, fecal coliforms, and E. coli) during the 2010 sampling season. 


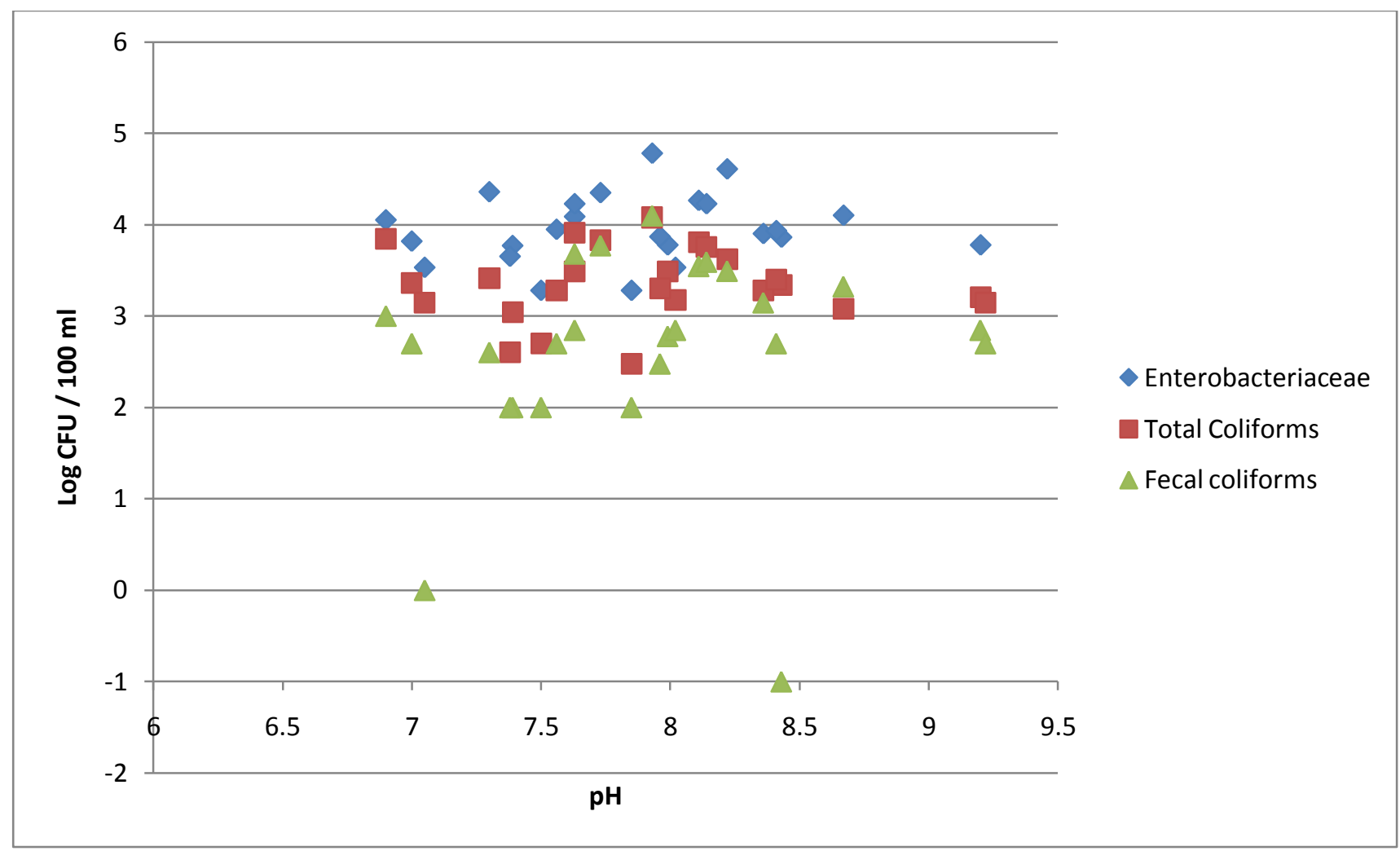

Figure 3-5. The effect of $\mathrm{pH}$ in $\mathrm{W}-\mathrm{S}$ on the growth of fecal indicator organisms (Enterobacteriaceae, total coliforms, and fecal coliforms) during the 2009 sampling season. 


\section{Chapter 4 : Overall Discussion and Conclusions}

The conclusion of this study was that the bacterial composition of water used for direct crop applications throughout the growing season did not have a consistent impact on the bacterial composition of the tomato fruit surface. Microbiological methods were used to determine the number of select fecal indicator organisms (Enterobacteriaceae, total coliforms, fecal coliforms, and E. coli) in water and phyllosphere samples. Similar results were obtained when molecular methodologies were used to analyze the same water and phyllosphere samples (Telias et al., 2011). 454 pyrosequencing was used to generate a 16s rRNA genetic library of the bacteria found in the groundwater source, surface water source, and on tomato phyllosphere samples with respective water treatments. In this study $39 \%$ of hits in the groundwater samples were from Enterobacteriaceae, much higher than the $2 \%$ observed in surface water. This may be due to the higher diversity of bacteria in the surface water, which had a higher species richness than the groundwater samples. Enterobacteriaceae was more abundant in phyllosphere than in water samples: $52.6 \%$ of the groundwater treated tomato phyllosphere and $33.85 \%$ of the surface water treated phyllosphere were Enterobacteriaceae (Telias et al., 2011).

A portion of the Enterobacteriaceae in the molecular study was comprised of the Klebsiella, Enterobacter, and Citrobacter genera. Although these three genera are environmental organisms and therefore are not indicative of fecal contamination, they are often selected for in microbiological tests for total coliforms and fecal coliforms. This is one reason that Enterobacteriaceae, total coliforms, and fecal coliforms are not regarded as accurate indicators of fecal contamination. Among the 2009 groundwater and surface water samples, no Klebsiella or Citrobacter species were found, although there were 7 hits for Enterobacter in the groundwater samples. The phyllosphere samples had higher quantities of the above organisms: 
Enterobacter was found in $33.1 \%$ of groundwater treated phyllosphere and $20.5 \%$ of surface water treated phyllosphere samples. Klebsiella and Citrobacter were found in less than $1 \%$ of the phyllosphere samples (Telias et al., 2011).

The presence of Klebsiella, Enterobacter, and Citrobacter in the phyllosphere as indicated by the molecular study suggests that these organisms are likely to have had an influence on the counts of fecal indicator organisms. A logical next step would be to clone and sequence 16S rRNA genes from individual colonies growing on inoculated Petrifilms. This would allow us to find the percentage of colonies that may be environmental organisms, as well as those that may be potentially pathogenic organisms or indicative of fecal contamination. Since Petrifilms are an industry-recognized tool in monitoring water and food quality, it would also be valuable to know the exact genera of organisms that the Petrifilms used (Enterobacteriaceae, total coliforms, fecal coliforms, and E. coli) select for.

The results from this study have implications on the agriculture industry. Current guidelines for microbial water testing encourage farmers to test their water "frequently", since water quality can change drastically in short amounts of time (Food Safety Initiative Staff 1998; Gombas, 2008). However, no suggestions are given as to the number or frequency of water samples required. Greater emphasis should be placed on the variability of water quality. Our results showed the counts of fecal coliforms in the surface ponds increased over $2 \operatorname{logs}$ in a week. If tomato producers test their agricultural water only once or twice a season, then it is possible that unsafe microbial loads may go unnoticed.

This study implies that significantly higher levels of indicator organisms in the water samples were not mirrored in the grape tomato phyllosphere. In 2009, the groundwater treated 
tomato fruit had significantly higher total coliforms, and the surface water treated tomato fruit had significantly higher levels of fecal coliforms. In 2010, the surface water treated tomato fruit had significantly higher levels of Enterobacteriaceae. Given the inconsistencies in counts of fecal indicator organisms in the phyllosphere data when organized by treatment, it is possible that other variables play an important role in determining the number of fecal indicator organisms, by either deactivating bacterial colonies, or promoting their growth. These variables may be environmental, such as precipitation, wind, ultraviolet light levels, and air temperature, as well as other sources of contamination, such as deer and birds. A preliminary analysis estimated that the cost of preventing one case of hepatitis A by decreasing the number of fecal coliforms in water from 1,000 to $0 \mathrm{CFU} / 100 \mathrm{ml}$ was between 3 to 30 million dollars (Blumenthal et al., 2000). Although the cost will be lower in the United States due to the low endemic risk of infection, the cost of sanitizing water to levels suitable for foliar application is expensive. Large amounts of water are needed for irrigation and pesticide applications, so often sources other than groundwater are used in agriculture.

Since this research was conducted using 'Juliet' grape tomatoes, the results may not necessarily be extrapolated to regular tomatoes or other crops. Tomatoes, regardless of variety, are grown using similar production methods in DelMarVa: on black plastic mulch, using a string system to support the plants and prevent soil contamination. Both grape and regular tomatoes have a textured stem scar, which may allow for bacterial attachment. However, little scientific information is available about the differences in bacterial colonization among tomato cultivars. The amount of surface area and levels of antimicrobials produced by tomato plants may differ by variety, thus influencing the food safety risk. There is currently a variety trial in Florida studying the differential growth of Salmonella on tomato cultivars (Anderson et al., 2010). 
As discussed in the manuscript, the groundwater spray catches had significantly higher counts than the samples taken directly from the source. Measures were taken to decrease contamination by rinsing out and properly storing the spray canisters and manifolds after treatment applications, flushing the manifolds out before treatment applications, and using a separate spray manifold for each treatment. However, the elevated counts of Enterobacteriaceae, total coliforms, and fecal coliforms in the spray catch samples indicated contamination. The buildup of pesticide residue in the sprayer may have led to the difference in counts by allowing the bacteria to attach and reproduce. It is possible that as water is flushed through for longer amounts of time, the bacterial counts decrease to levels similar to the source samples. Further testing will be done next spring to investigate the possible sources of contamination in the spray catch samples. If this research were to be run again in the future, more emphasis would be placed on monitoring the spray catch samples. 


\section{Appendices}

A. Map of Grape tomato plots (2009 and 2010) at Wye Research and Education Center (WREC). 'Trees' indicates a forested area 30 feet from tomato plot.

Wye Plots: 2009

\section{Trees}
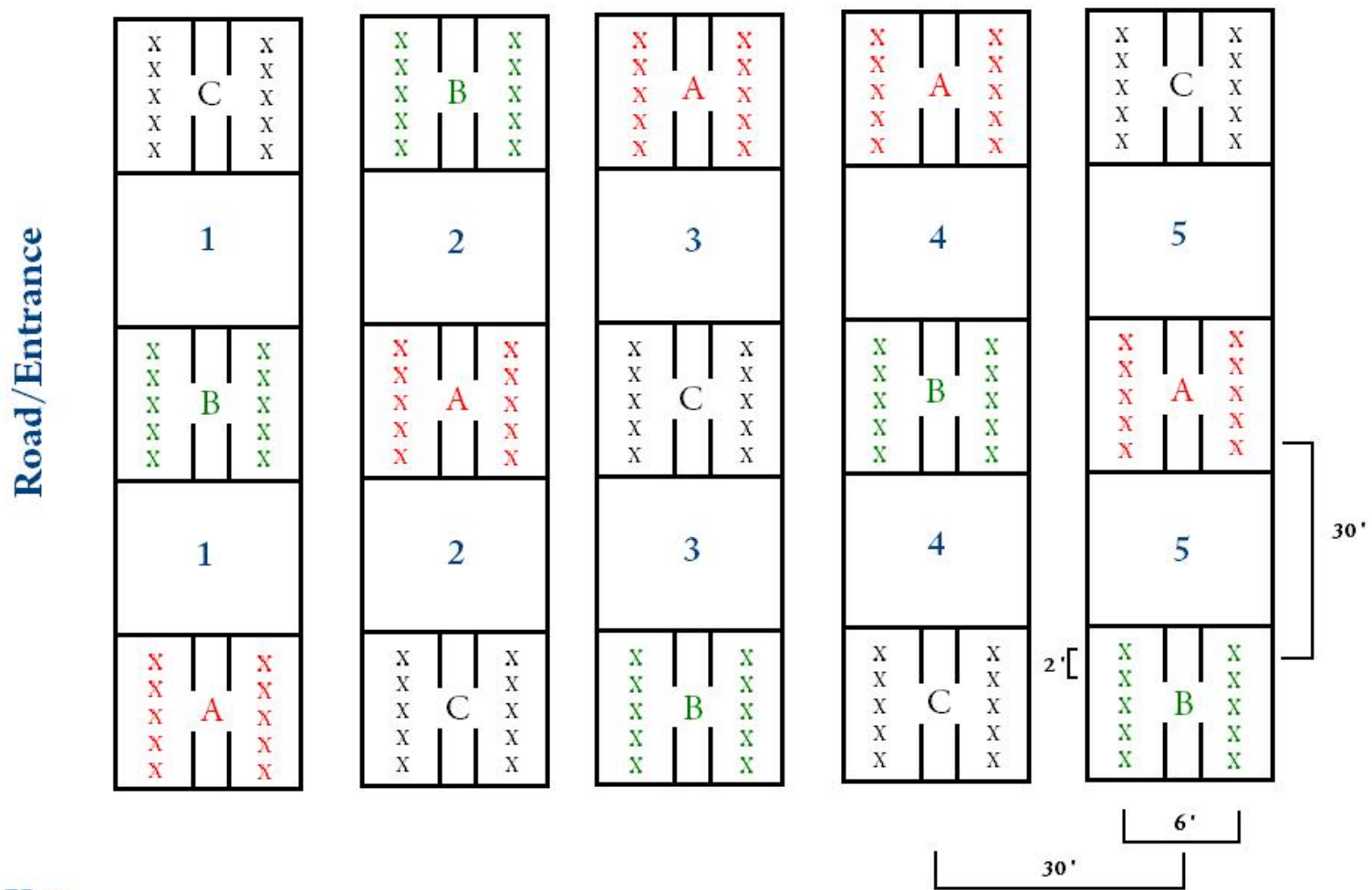

Key

A = groundwater

$\mathrm{B}=\mathrm{CuSO} 4$

$\mathrm{C}=$ surface water 
Wye Plots: 2010

Trees
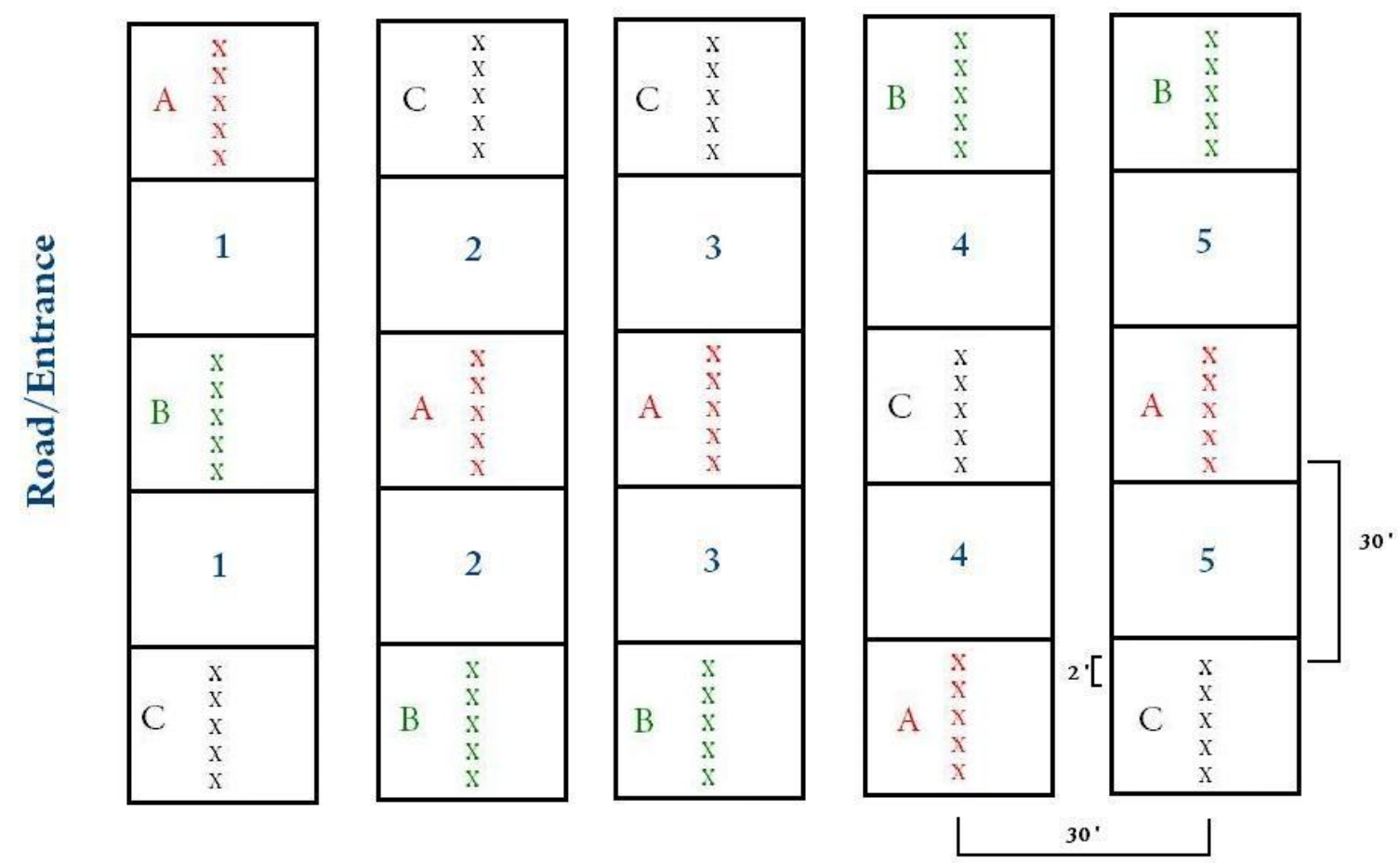

Key

$\mathrm{A}=$ groundwater

$\mathrm{B}=\mathrm{CuSO} 4$

$C=$ surface water 
B. Photo of spray manifold used to apply treatments

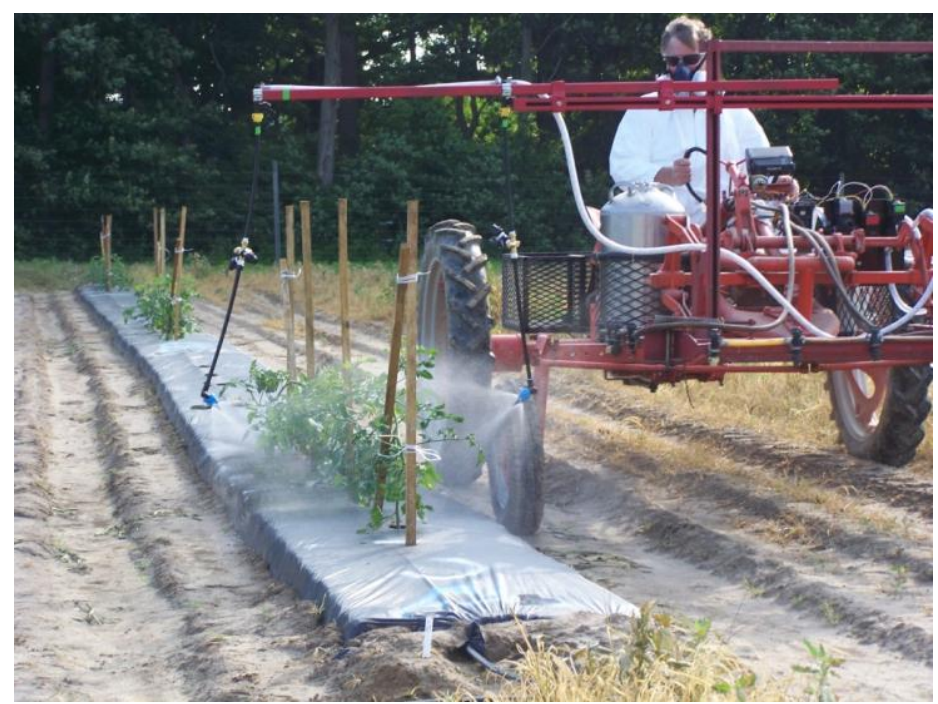

Photos of water sources (left to right, W-G, W-S, W-CS)
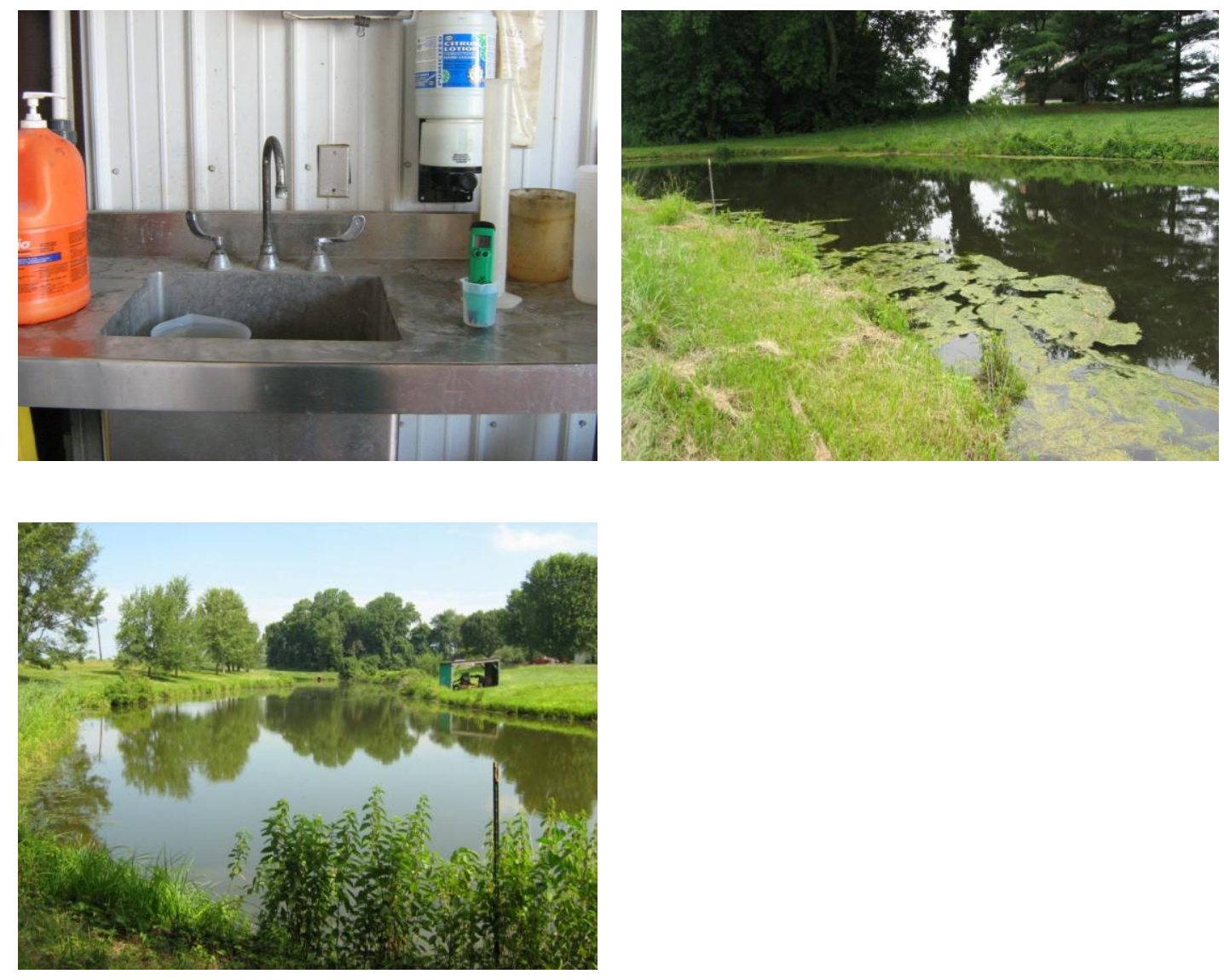
C. Spray schedules at the grape tomato field plots at WREC for the 2009 and 2010 sampling seasons.

\author{
2009 Work Log/Spray Treatments \\ Food Safety Plots/Tomato \\ Wye Research Center
}

May 28 Fertilize pre plant, $60 \mathrm{lb}$ nitrogen/acre, Lay plastic

June 7 Apply herbicides between rows, Dacthal + Sandea

June 10 Plant, water with transplant fertilizer (20-20-20) @ 5 lbs/100 gallon,

Apply Admire insecticide with transplant water @ $0.1 \mathrm{oz} / 1000$ plants

June 16 Spray all with Spintor + Bravo...NO Spray water treatments

June 19 Fertigate to apply 15-15-15

June 22 Install stakes

June $30^{\text {th }} \quad$ Prune and apply first string

July 2 Apply $1^{\text {st }}$ spray treatments, Bravo + Entrust

July $7^{\text {th }} \quad$ Tie $2^{\text {nd }}$ string

July 14 Apply $2^{\text {nd }}$ spray treatments, Bravo + Entrust

July $21 \quad$ Fertigate to apply 15-15-15

July 28 Apply $3^{\text {rd }}$ spray treatments, Bravo + Entrust + Cabrio

August $4^{\text {th }} \quad$ Tie $3^{\text {rd }}$ string

August $9^{\text {th }} \quad$ Apply $4^{\text {th }}$ spray treatments, Bravo + PreviclorFlex + Entrust

August 11 Tie $4^{\text {th }}$ string

August $20^{\text {th }}$ Apply $5^{\text {th }}$ spray treatment Bravo + Entrust + Agrimek

August $25^{\text {th }}$ Treat pond with Copper

August $30^{\text {th }}$ Apply $6^{\text {th }}$ spray treatment, Bravo + Entrust + Agrimek

August 31 shake off excess grape tomatoes 
September 10 Apply final spray treatments, Bravo + Entrust + Agrimek

\author{
2010 Work Log/Spray Treatments \\ Food Safety Plots/Tomato \\ Wye Research Center
}

June 2 Planted tomato plants

June $4 \quad$ Treat pond with copper

July 3 Apply Bravo and Kocide with airblast spray using only groundwater

July 26 Application of Bravo and Entrust with spray treatments

August 8 Application of Bravo and Entrust with spray treatments

August 22 Application of Bravo and Entrust with spray treatments

August 30 Application of Bravo and Entrust with spray treatments

September 7 Application of Bravo and Entrust with spray treatments 


\section{Example SAS codes for ANOVA and regression analyses}

Repeated measures ANOVA on water data:

proc print data $=$ water;

run;

proc mixed data=water;

class source rep julian;

model Elog=source julian source $*$ julian $/$ ddfm $=\mathrm{kr}$;

random rep;

repeated julian/subject $=$ source(rep) type $=c s$;

lsmeans source*julian / adj=tukey;

run;

proc mixed data=water;

class source rep julian;

model TClog=source julian source*julian/ ddfm $=\mathrm{kr}$;

random rep;

repeated julian/subject $=$ source $($ rep $)$ type $=c s$;

lsmeans source*julian / adj=tukey;

run;

proc mixed data $=$ water;

class source rep julian;

model fclog=source julian source $*$ julian $/ \mathrm{ddfm}=\mathrm{kr}$;

random rep;

repeated julian/subject $=$ source $($ rep $)$ type $=c s$;

lsmeans source*julian / adj=tukey;

run;

Stepwise regression analysis on water data:

proc print data=water;

run;

proc reg data $=$ water;

model Elog= source 2 julian $\mathrm{pH}$ watertemp maxairtemp precip3day/selection=stepwise;

run;

proc reg data=water;

model TClog= source 2 julian $\mathrm{pH}$ watertemp maxairtemp precip3day/selection=stepwise;

run;

proc reg data $=$ water;

model fclog= source 2 julian $\mathrm{pH}$ watertemp maxairtemp precip3day/selection=stepwise;

run;

proc reg data=water;

model Eclog=source2 julian $\mathrm{pH}$ watertemp maxairtemp precip3day/selection=stepwise;

run;

Repeated measures ANOVA on grape phyllosphere data:

proc print data=grape;

run;

proc mixed data=grape; 
class treat rep julian;

model Elog $=$ treat julian treat $*$ julian $/ \mathrm{ddfm}=\mathrm{kr}$; random rep;

repeated julian/subject $=$ treat(rep) type $=\mathrm{cs}$;

lsmeans treat julian/adj=tukey;

run;

proc mixed data=grape;

class treat rep julian;

model $\mathrm{TClog}=$ treat julian treat*julian/ddfm $=\mathrm{kr}$;

random rep;

repeated julian/subject $=$ treat(rep) type $=c s$;

lsmeans treat julian/adj=tukey;

run;

proc mixed data=grape;

class treat rep julian;

model fclog $=$ treat julian treat $*$ julian $/ \mathrm{ddfm}=\mathrm{kr}$; random rep;

repeated julian $/$ subject $=$ treat(rep) type $=\mathrm{cs}$;

lsmeans treat julian/adj=tukey;

run;

proc mixed data=grape;

class treat rep julian;

model Eclog $=$ treat julian treat $*$ julian $/ \mathrm{ddfm}=\mathrm{kr}$;

random rep;

repeated julian/subject $=$ treat(rep) type $=\mathrm{cs}$;

lsmeans treat julian/adj=tukey;

run; 


\section{References}

3M (2006a). Petrifilm coliform count plate. In Interpretation guide (St. Paul, 3M Microbiology).

3M (2006b). Petrifilm E. coli/Coliform count plate. In Interpretation guide (St. Paul, 3M Microbiology).

3M (2006c). Petrifilm Enterobacteriaceae count plate. In Interpretation guide (St. Paul, 3M Microbiology).

Alonso, J.L., Soriano, A., Carbajo, O., Amoros, I., and Garelick, H. (1999). Comparison and recovery of Escherichia coli and thermotolerant coliforms in water with a chromogenic medium incubated at 41 and 44.5 degrees C. Appl Environ Microbiol 65, 3746-3749.

Anderson, M., and Teplitzski, M. (2010). UF research finds salmonella responds differently to tomato varieties, ripeness.

Anonymous (2000). 3M Petrifilm E. coli/Coliform Count Plates, Carolina Biological Supply Company.

Baker, C.M., Chitrakar, R., Obulareddy, N., Panchal, S., Williams, P., and Melotto, M. (2010). Molecular battles between plant and pathogenic bacteria in the phyllosphere. Brazilian $\mathrm{J}$ Med Biol Res 43, 698-704.

Barak, J.D., and Liang, A.S. (2008). Role of soil, crop debris, and a plant pathogen in Salmonella enterica contamination of tomato plants. PLoS One 3, 5.

Beuchat, L.R. (2002). Ecological factors influencing survival and growth of human pathogens on raw fruits and vegetables. Microbes and Infection 4, 413-423.

Blood, R.M., and Curtis, G.D.W. (1995). Media for total Enterobacteriaceae, coliforms, and Escherichia coli. Int J Food Microbiol 26, 93-115.

Blumenthal, U.J., Mara, D.D., Peasey, A., Ruiz-Palacios, G., and Stott, R. (2000). Guidelines for the microbiological quality of treated wastewater used in agriculture: recommendations for revising WHO guidelines. Bulletin of the World Health Organization 78, 1104-1113.

Buchanan, R. (2010). Food spoilage: Fresh and fresh-cut produce (College Park).

Burau, R., Sheikh, B., Cort, R., Cooper, R., and Ririe, D. (1987). Reclaimed water for irrigation of vegetables eaten raw. California Agriculture, 4-7.

Chandran, A., and Hatha, A.A.M. (2005). Relative survival of Escherichia coli and Salmonella typhimurium in a tropical estuary. Water Research 39, 1397-1403.

Cummings, K.J., Warnick, L.D., Elton, M., Grohn, Y.T., McDonough, P.L., and Siler, J.D. (2010). The effect of clinical outbreaks of salmonellosis on the prevalence of fecal salmonella shedding among dairy cattle in New York. Foodborne Pathog Dis 7, 815-823.

Daly, E.R., Smith, C.M., Wikoff, P., Seiferth, J., Finnigan, J., Nadeau, A.M., and Welch, J.J. (2010). Salmonella enteritidis infections associated with a contaminated immersion blender at a camp. Foodborne Pathog Dis 7, 1083-1088.

Danhorn, T., and Fuqua, C. (2007). Biofilm formation by plant-associated bacteria. Annu Rev Microbiol 61, 401-422.

Enya, J., Koitabashi, M., Shinohara, H., Yoshida, S., Tsukiboshi, T., Negishi, H., Suyama, K., and Tsushima, S. (2007a). Phylogenetic diversities of dominant culturable Bacillus, Pseudomonas and Pantoea species on tomato leaves and their possibility as biological control agents. Journal of Phytopathology 155, 446-453.

Enya, J., Shinohara, H., Yoshida, S., Tsukiboshi, T., Negishi, H., Suyama, K., and Tsushima, S. (2007b). Culturable leaf-associated bacteria on tomato plants and their potential as biological control agents. Microbial Ecology 53, 524-536. 
EPA (2002). 40 CFR 131.41 c Maximum contaminant levels for microbiological contaminants, United States Environmental Protection Agency.

EPA (2008). 131.41c Ambient water quality criteria for bacteria, United States Environmental Protection Agency.

Epstein, L., and Bassein, S. (2001). Pesticide applications of copper on perennial crops in California, 1993 to 1998. Journal of Environmental Quality 30, 1844-1847.

Fan, X., Niemira, B., Doona, C., Feeherry, F., and Gravani, R., eds. (2009). Microbial Safety of Fresh Produce (Ames, Wiley-Blackwell ).

FAO (2008). FAOSTAT (Food and Agriculture Organization).

Fonseca, J. (2006). Postharvest handling and processing: sources of microorganisms and impact of sanitizing procedures. In Microbiology of fresh produce, K.R. Matthews, ed. (Washington D.C., ASM Press), pp. 85-120.

Food Safety Initiative Staff. (1998). Guide to minimize microbial food aafety hazards for fresh fruits and vegetables, Center for Food Safety and Applied Nutrition. (CFSAN), ed. (Washington DC, Food and Drug Administration), pp. 1-49.

Friedman, M. (2002). Tomato glycoalkaloids: role in the plant and in the diet. Agricultural and Food Chemistry 50, 5751-5780.

Gombas, D. (2008). Commodity specific food safety guidelines for the fresh tomato supply chain, United Fresh produce association, ed., pp. 8-53.

Guan, T.T.Y., Blank, G., and Holley, R.A. (2004). Survival of pathogenic bacteria in pesticide solutions and on treated tomato plants. J Food Prot 68, 296-304.

Guo, X., Chen, J.R., Brackett, R.E., and Beuchat, L.R. (2001). Survival of salmonellae on and in tomato plants from the time of inoculation at flowering and early stages of fruit development through fruit ripening. Appl Environ Microbiol 67, 4760-4764.

Hayes, W.A., Smith, P.G., and Morris, A.E.G. (1998). The production and quality of tomato concentrates. Critical Reviews in Food Science and Nutrition 38(7):537-564 (1998), 537564.

Hong, C., Lea-Cox, J.D., Ross, D.S., Moorman, G.W., Richardson, P.A., Ghimire, S.R., and Kong, P. (2009). Containment basin water quality fluctuation and implications for crop health management. Irrigation Science 27, 485-496.

Jay, J.M. (1992). Modern Food Microbiology, Fourth edition edn (New York, Chapman and Hall).

Marks, B. (2005). A brief introduction to microbiology and the use of 3M petrifilm plates., S. Biological, ed., pp. 1-15.

Matthews, K.R., ed. (2006). Microbiology of Fresh Produce (Washington, DC, ASM Press).

Mead, P.S., Slutsker, L., Dietz, V., McCaig, L.F., Bresee, J.S., Shapiro, C., Griffin, P.M., and Tauxe, R.V. (1999). Food-Related Illness and Death in the United States.

Montville, T.J., and Matthews, K.R. (2008). Food Microbiology: An Introduction, 2nd edn (Washington, DC, ASM Press).

Obi, C., Igumbor, J., Momba, M., and Samie, A. (2008). Interplay of factors involving chlorine dose, turbidity flow capacity and $\mathrm{pH}$ on microbial quality of drinking water in small water treatment plants. Water SA 34, 565-572.

Oliver, D.M., Fish, R.D., Hodgson, C.J., Heathwaite, A.L., Chadwick, D.R., and Winter, M. (2009). A cross-disciplinary toolkit to assess the risk of faecal indicator loss from grassland farm systems to surface waters. Agric Ecosyst Environ 129, 401-412. 
Or, D., Phutane, S., and Dechesne, A. (2007). Extracellular polymeric substances affecting porescale hydrologic conditions for bacterial activity in unsaturated soils. Vadose Zone $\mathrm{J} 6$, 298-305.

Parsek, M., and Greenberg, E.P. (2000). Acyl-homoserine lactone quorum sensing in Gramnegative bacteria: a signaling mechanism involved in associations with higher organisms. Proceedings of the National Academy of Sciences 97, 8789-8793.

Paulsen, P., Borgetti, C., Schopf, E., and Smulders, F.J.M. (2007). Enumeration of Enterbacteriaceae in various foods with a new automated most-probable-number method compared with petrifilm and international organization for standardization procedures. Journal of Food Protection 71, 376-379.

Pearson, A., Roberts, M., Soge, O., Ivanova, I., Mayer, J., and Meschke, J. (2008). Utility of EC $3 \mathrm{M}$ Petrifilm and sanitary surveys for source water assessment in Nyashozi county, south-western Uganda. South African Water research commission 34, 279-284.

Putnam, J.J., and Allshouse, J.E. (1999). Food consumption, prices, expenditures, 1970-97, United States Department of Agriculture Economic Research Service, ed., pp. 17-25.

RapidChek (2010). RapidChek® SELECT ${ }^{\text {TM }}$ Salmonella enteritidis test system quick guide. In Strategic Diagnostics (Newark).

Sajur, S.A., Saguir, F.M., and de Nadra, M.C.M. (2007). Effect of dominant specie of lactic acid bacteria from tomato on natural microflora development in tomato puree. Food Control 18, 594-600.

Schultz-Fademrecht, C., Wichern, M., and Horn, H. (2008). The impact of sunlight on inactivation of indicator microorganisms both in river water and benthic biofilms. Water Research 42, 4771-4779.

Sengor, S.S., Barua, S., Gikas, P., Ginn, T.R., Peyton, B., Sani, R.K., and Spycher, N.F. (2009). Influence of heavy metals on microbial growth kinetics including lag time: mathematical modeling and experimental verification. Environ Toxicol Chem 28, 2020-2029.

Sivapalasingam, S., Friedman, C.R., Cohen, L., and Tauxe, R.V. (2004). Fresh produce: A growing cause of outbreaks of foodborne illness in the United States, 1973 through 1997. J Food Prot 67, 2342-2353.

Sylvia, D.M., Hartel, P.G., Fuhrmann, J.F., and Zuberer, D.A. (2005). Principles and applications of soil microbiology, 2nd edition edn (Upper Saddle River Pearson Prentice Hall).

Tallon, P., Magajna, B., Lofranco, C., and Leung, K.T. (2005). Microbial indicators of faecal contamination in water: A current perspective. Water Air Soil Pollut 166, 139-166.

Telias, A., White, J.R., Pahl, D.M., Ottesen, A.R., and Walsh, C.S. (2011). Bacterial community diversity and variation in spray water sources and the tomato phyllosphere (In review). BMC Microbiology 00, 00-00.

UC (2007). Eliminate fecal coliforms from your food safety vocabulary. In University of California Good Agricultural Practices.

Wells, H.F., and Buzby, J.C. (March 2008). Dietary Assessment of Major Trends in U.S. Food Consumption, 1970-2005, E.R. Service/USDA, ed., pp. 1-27. 